\title{
EXPECTATIVAS Y MOTIVACIONES DEL TURISTA ALEMÁN
}

\author{
Sonia Agüero de Becker \\ Instituto Latinoamericano, Universidad Libre de Berlin \\ Embajada del Perú en Alemania
}

El turismo es un proceso complejo que comprende un gran número de dimensiones (culturales, políticas, socioeconómicas, ambientales, psicológicas) e involucran a diversos sectores no siempre con los mismos intereses ni con los mismos objetivos, sino muchas veces en sentidos opuestos.

En este sentido, queremos encaminar nuestro ensayo en el aspecto etnográfico del turismo (cómo funciona y cómo se da en la practica) para luego proponer una ética del turismo de cómo quisiéramos que se hiciera.

A la luz de estas dos vertientes entre lo descriptivo y lo normativo presentaremos los resultados de nuestra investigación realizada, en base a la aplicación de una encuesta y entrevistas múltiples a los eventuales y reales turistas alemanes, en la ciudad de Berlin durante los meses de octubre del 2002 a abril del 2003.

El universo de estudio estuvo constituído por los alemanes residentes en Berlin que tenían cierta conexión con el Perú, como por aquellos que nunca habían estado en el Perú.

Se aplicó un cuestionario a 217 personas en los diferentes distritos de la ciudad en los centros de trabajo, universidades, academias de idiomas, bibliotecas, instituciones o asociaciones gremialistas y al ciudadano alemán en general.

\section{PERFIL DEL TURISTA ALEMÁN.}

Un análisis de la estructura demográfica del turista alemán nos remite a los siguientes resultados.

\subsection{Edad y sexo de los entrevistados.}

Al examinar la estructura poblacional de los turistas alemanes (Ver diagrama $N^{\circ} 1$ ) observamos los siguientes intervalos de edades. El primero, conformado por una población entre $\operatorname{los} 18$ y 50 años que representa el $36 \%$.Tomamos como edad mínima los 18 , porque es cuando el joven adquiere su mayoría de edad y ciudadanía. El segundo intervalo está representado por las edades entre los 35 y 30 años, es decir, el $46 \%$ que a su vez,por lo general, es el turista más establecido económica y psicológicamente que se anima a realizar un viaje a larga distancia con muchas horas de vuelo. El tercer grupo que corresponde al $18 \%$ lo constituye la personas con más de 50 años que prefieren como destino turístico ciudades europeas, antes que ciudades latinoamericanas. 


\section{Diagrama $\mathrm{N}^{\circ}$ 1. Edad de los entrevistados}

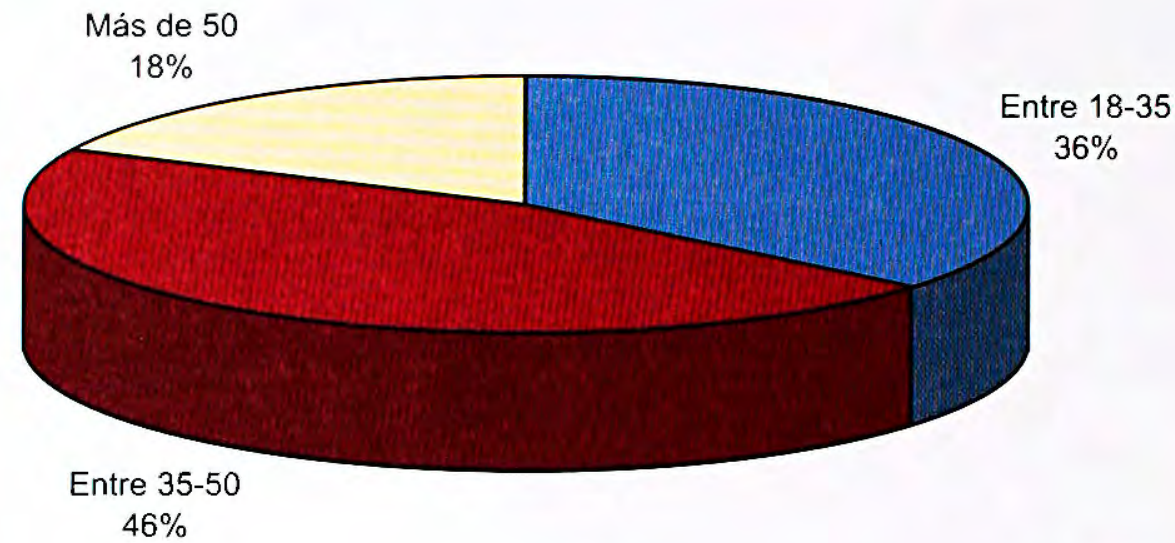

El 12\% corresponde a los estudiantes que en la mayoría de los casos se limitan sólo a la compra de los billetes de avión, estando la permanencia en los centros de destino por su cuenta. En otros casos, les son donados los billetes de avión por alguna fundación académica o por la misma universidad. El tiempo de permanencia en el país de destino es de aproximadamente entre dos o tres meses, pudiendose extender hasta los seis en caso de la realización de alguna práctica preprofesional. Este sector de jóvenes podrían ser los mejores "vendedores de nuestra cultura peruana" en Alemania. Su capacidad de apertura a otros contextos, su curiosidad académica innovadora y la transmisión de los "buenos recuerdos" a sus amigos y conocidos serían las condiciones para una exitosa promoción turística.

El pensionista con el $8 \%$ prefiere su tranquilidad y "lo conocido", mientras que el desempleado con el $3 \%$ tiene poco o nada que decidir ante un eventual viaje de turismo.

El tipo de economía de los potenciales turistas está directamente ligado a sus ingresos económicos. (Ver diagrama $\mathrm{N}^{\circ} 3$ )
Así, el $42 \%$ de los entrevistados mencionó tener un ingreso anual entre los 30,000 y 60,000 euros, lo que correspondería a un alemán con un tipo de vida del nivel medio. Este grupo combina sus viajes de vacaciones entre Sudamérica, Central América (República Dominicana y Cuba) y Norte América (México)

El segundo grupo que es el $41 \%$ tiene como ingresos una media entre los 15,000 y 30,000 euros. Ellos consideraron que un viaje a Sudamérica es bastante caro y fuera del alcance de sus posibilidades. Ellos prefieren hacer pequeñas excursiones a ciudades cercanas dentro del territorio alemán o viajes a la Europa del Este ( Polonia , Rumanía, Hungría, Bulgaria, etc)

El $13 \%$ con un ingreso anual de menos de 15,000 euros tiene una capacidad de viaje bastante reducida o casi nula.

En cuanto a los ingresos superiores por encima de los 60,000 anuales no se encontró ningún caso representativo. La explicación podría estar dada o por los lugares donde se realizó la entrevista (universidades bibliotecas etc), o porque el ciudadano alemán "de a pie" no supera este tipo de ingresos. 
Diagrama N² Ocupación de los entrevistados

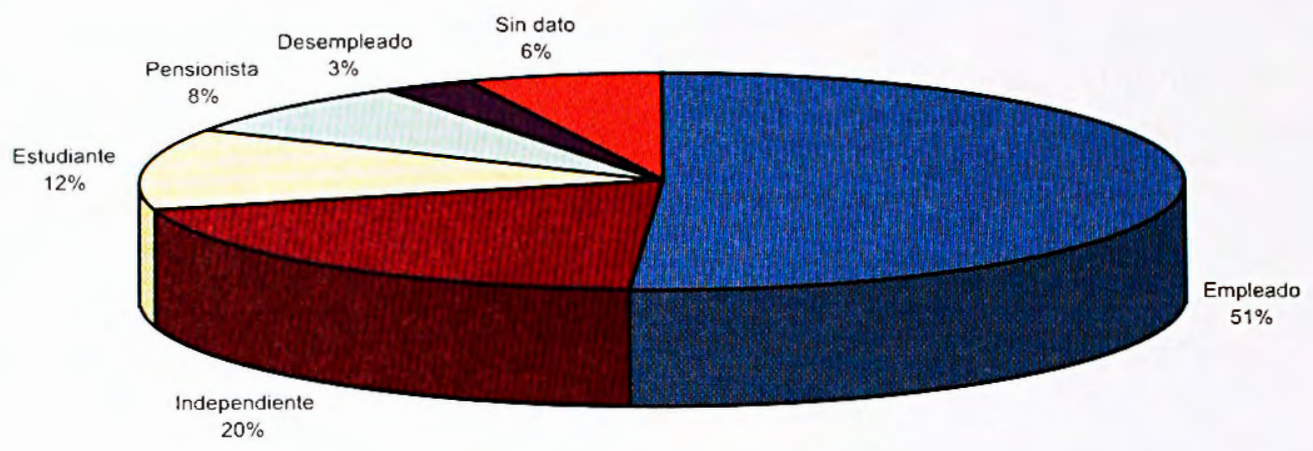

Diagrama $\mathrm{N}^{\circ} 3$ Ingresos en euros de los turistas alemanes

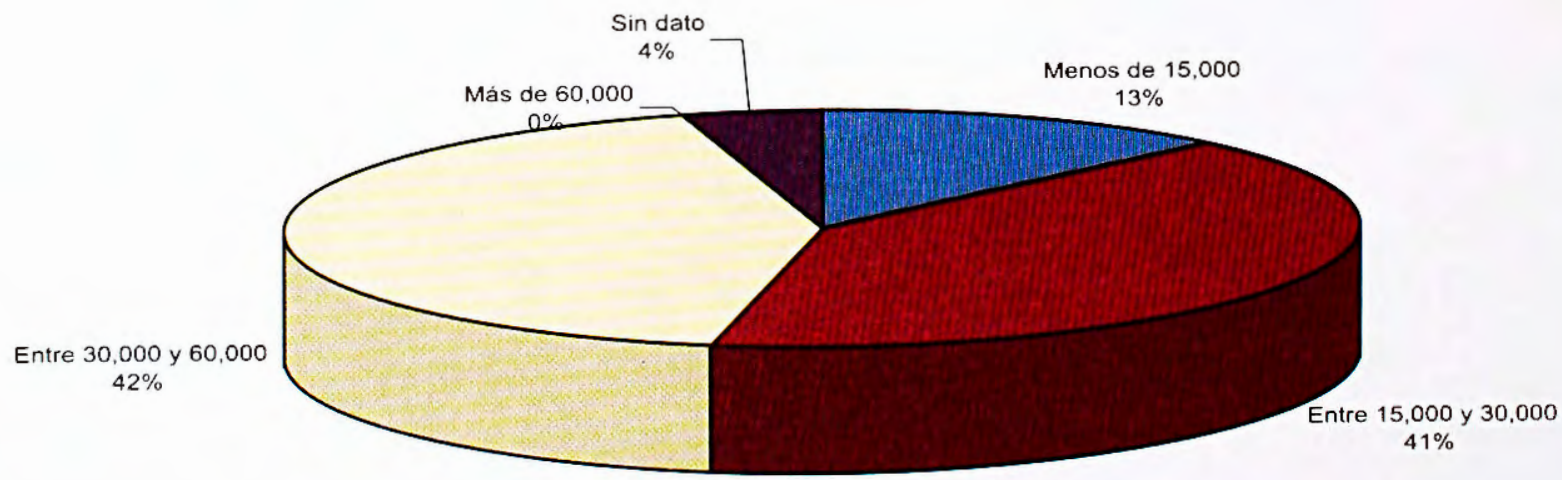


En este sentido,nuestra captación del potencial turista debe orientarse al primer sector de turistas es decir al representado por el $42 \%$. Son los más receptibles a los viajes al extranjero. Una canalización o reorientación de sus preferencias por América Central hacia Sudamérica, y en nuestro caso al Perú sería una de las alternativas. Son poblaciones de turismo que están dispuestas a hacer largos viajes y que además cuentan con la suficiente capacidad adquisitiva para hacerlo.

En lo referente al estado civil de nuestra población entrevistada tenemos un $47 \%$ registrada como soltera, un $35 \%$ como casada y un $18 \%$ perteneciente a otro tipo de estado civil'.

El primer grupo, es decir el $47 \%$, nos da una mejor idea de la capacidad de movimiento del poblador alemán. No es una categoría definitiva de a mayor número de solteros, mayor número de viajes, pero si una orientación en la búsqueda de la población objetivo de turismo.

\section{Características del viaje de turismo.}

En este acápite queremos identificar algunas de las características básicas del turista alemán, sus comportamientos, intereses, y motivaciones.

Según la F.U.R.(Forschungsgemeinschaft Urlaubs und reisen e.V.), en su publicación anual $N^{\circ} 34$ Reiseanalyse Aktuell, R.A. 2004) para el año 2003 se identificaron 495 millones de vacacionistas alemanes con una duración promedio de viaje de un mínimo de 5 días. La intensidad de viaje para el año 2003 permaneció igual a la del año 2002, es decir, del 76,8\%. La dínámica de la capacidad de viaje residió en la relación entre la dirección del viaje y el volúmen o número de viajeros.

En el cuadro $N^{\circ} 1$ que presentamos a continuación observamos las tendencias de viaje de los turistas alemanes.

A los 66 millones de personas que realizaron turismo debemos agregar los 14 millones correspondientes a los menores de 14 años.

Si comparamos estas fuentes con nuestros datos vemos la siguiente correspondencia. La capacidad de viaje al extranjero, según nuestra encuesta ,es del $65 \%$. Le sigue un $32 \%$ que manifiesta una cierta regularidad en sus viajes fuera del país, para finalmente encontrar sólo un $3 \%$ que no hace turismo. (Ver diagrama ${ }^{\circ} 4$ )

Cuadro $N^{\circ} 1$

\begin{tabular}{|c|c|c|c|c|}
\hline \multirow{2}{*}{ R.A 2004} & \multirow{2}{*}{$\begin{array}{c}\text { Turismo en Cifras } \\
1994\end{array}$} & \multicolumn{2}{|c|}{ F.U.R } & \multirow[b]{2}{*}{2003} \\
\hline & & 1998 & 2002 & \\
\hline Pobla.(14 A.Mill) & 62,7 & 63,5 & 64,3 & 64,4 \\
\hline $\begin{array}{l}\text { Uno o más viajes } \\
\text { Intensidad \% }\end{array}$ & 78,1 & 76,4 & 75,3 & 76,8 \\
\hline Número viajeros & 49,0 & 48,5 & 48,4 & 49,5 \\
\hline Capacidad de viaje & 1,37 & 1,31 & 1,30 & 1,34 \\
\hline $\begin{array}{l}\text { Número de dias } \\
5 \text { y mas }\end{array}$ & 67,2 & 63,4 & 63,1 & 66,1 \\
\hline
\end{tabular}

'Las uniones de parejas en Alemania se dan mayormente sin el proceso contractual del matrimonio civil o religioso. 


\section{Diagrama $\mathrm{N}^{\circ} 4$ Frecuencia de viaje del turista alemán}

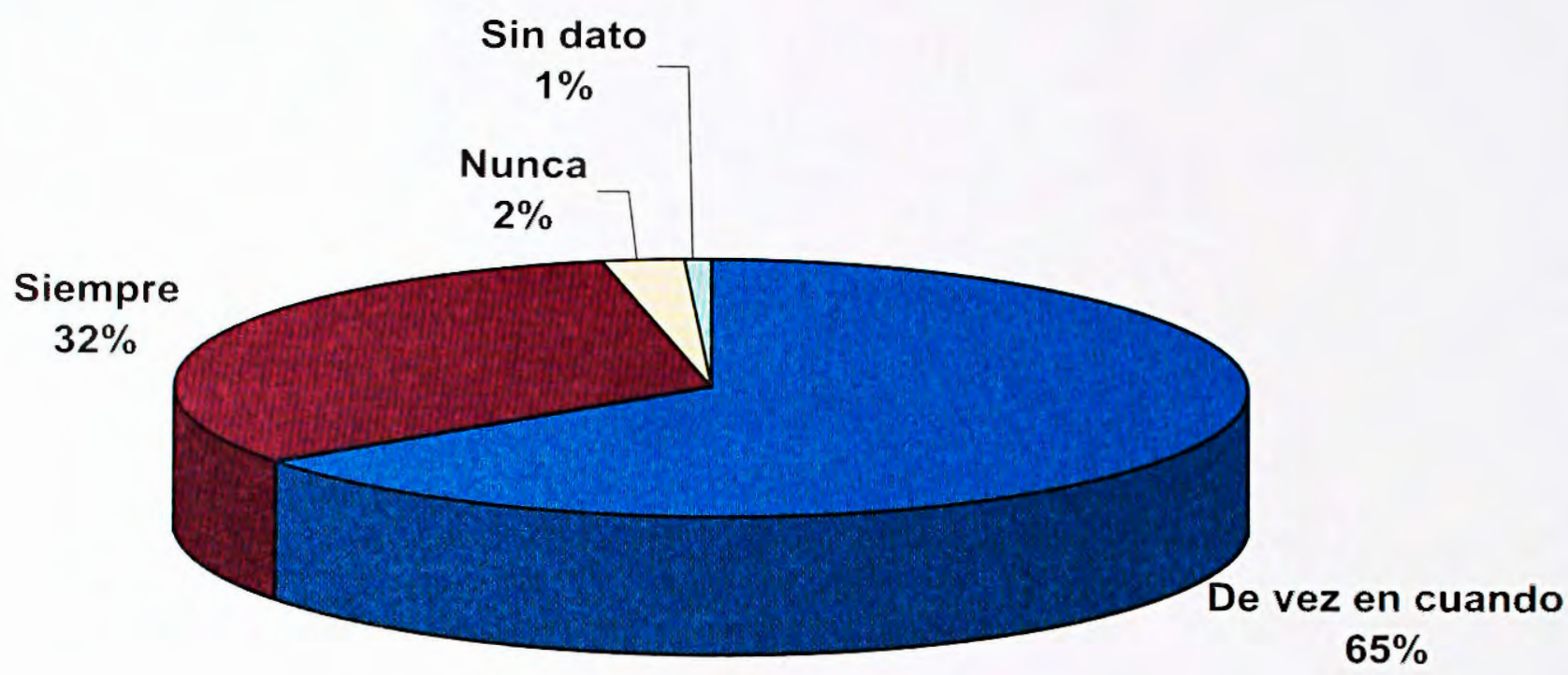

\subsection{Destinos turísticos.}

Aproximadamente, casi el $33 \%$ prefiere hacer turismo al interior de Alemania. Un segundo grupo, el $27 \%$, prefiere la zona europea del Mar Mediterraneo y el $14 \%$ la región de Europa Occidental. Los tradicionales países de Europa Occidental están siendo lentamente desplazados por los países escandinavos como Dinamarca, Noruega, Suecia o Finlandia. Ellos ofrecen la marca de lo "avanzado", "lo desconocido" y "lo tranquilo".Los viajes a larga distancia ocupan la última posición en la escala porcentual con apenas el $5 \%$. (Ver cuadro $\mathrm{N}^{\circ} 2$ )

En el extranjero, lugares preferenciales para realizar turismo son: España, Italia, Austria y Turquía. Pero se unen a las demandas en los últimos años países como Croacia, y países de Europa del Este como Bulgaria, Polonia, y Hungría. ( Ver diagrama $N^{\circ} 5$ )
En Alemania el turismo para el año 1998 no descendió. En 1991 fue del $40 \%$ y en 1998 el $43 \%$.Todavía no se puede hablar de un "ahorro en las vacaciones".

El $70 \%$ de los ciudades alemanes no desean disminuir su capacidad de turismo en los próximos años, pero tampoco se ven afectados financieramente por los viajes de vacaciones. Particularmente, en los viajes de larga distancia, el $43 \%$ manifiesta su deseo de una planificación económica previa antes que llenar una motivación personal.

Para mantener el ritmo de viaje de los últimos años el turista alemán se atiene a las ofertas de viaje de "último minuto". Una diferencia entre el ciudadano alemán del este y del oeste, es que el primero gusta hacer un turismo de compras, mientras que el segundo prefiere viajes no tan largos. 


\section{Cuadro $\mathrm{N}^{\circ} 2$}

\begin{tabular}{|c|c|c|c|c|c|}
\hline R.A 2004 & \multicolumn{2}{|c|}{ Destinos Turisticos 200 } & \multicolumn{2}{|c|}{ F.U.R. } & \\
\hline & $\begin{array}{c}1994 \\
\%\end{array}$ & $\begin{array}{c}1998 \\
\%\end{array}$ & $\begin{array}{c}2002 \\
\%\end{array}$ & $\begin{array}{c}2003 \\
\%\end{array}$ & Mill. \\
\hline Alemania & 34,9 & 29,6 & 30,5 & 32,6 & 21,5 \\
\hline Extranjero & 65,1 & 70,4 & 69,5 & 67,4 & 44,6 \\
\hline Mediterraneo (EU) & 25,4 & 28,4 & 28,6 & 26,6 & 17,6 \\
\hline Mediterraneo (REST) & 4,4 & 5,7 & 7,8 & 8,5 & 5,6 \\
\hline E.U. Occidental & 18,0 & 17,0 & 15,8 & 14,4 & 9,5 \\
\hline E.U. Oriental & 4,9 & 6,0 & 6,4 & 7,3 & 4,8 \\
\hline Escandinavia & 3,9 & 3,4 & 3,2 & 3,3 & 2,2 \\
\hline Viajes Distantes & 6,2 & 7,6 & 5,3 & 5,1 & 3,4 \\
\hline $\begin{array}{l}\text { Base todos los } \\
\text { Vacacionistas } \\
\text { (en millones) }\end{array}$ & 67,2 & 63,4 & 63,1 & & 66,1 \\
\hline
\end{tabular}

\section{Diagrama $\mathrm{N}^{\circ} 5$ Destinos Turísticos en el extranjero}

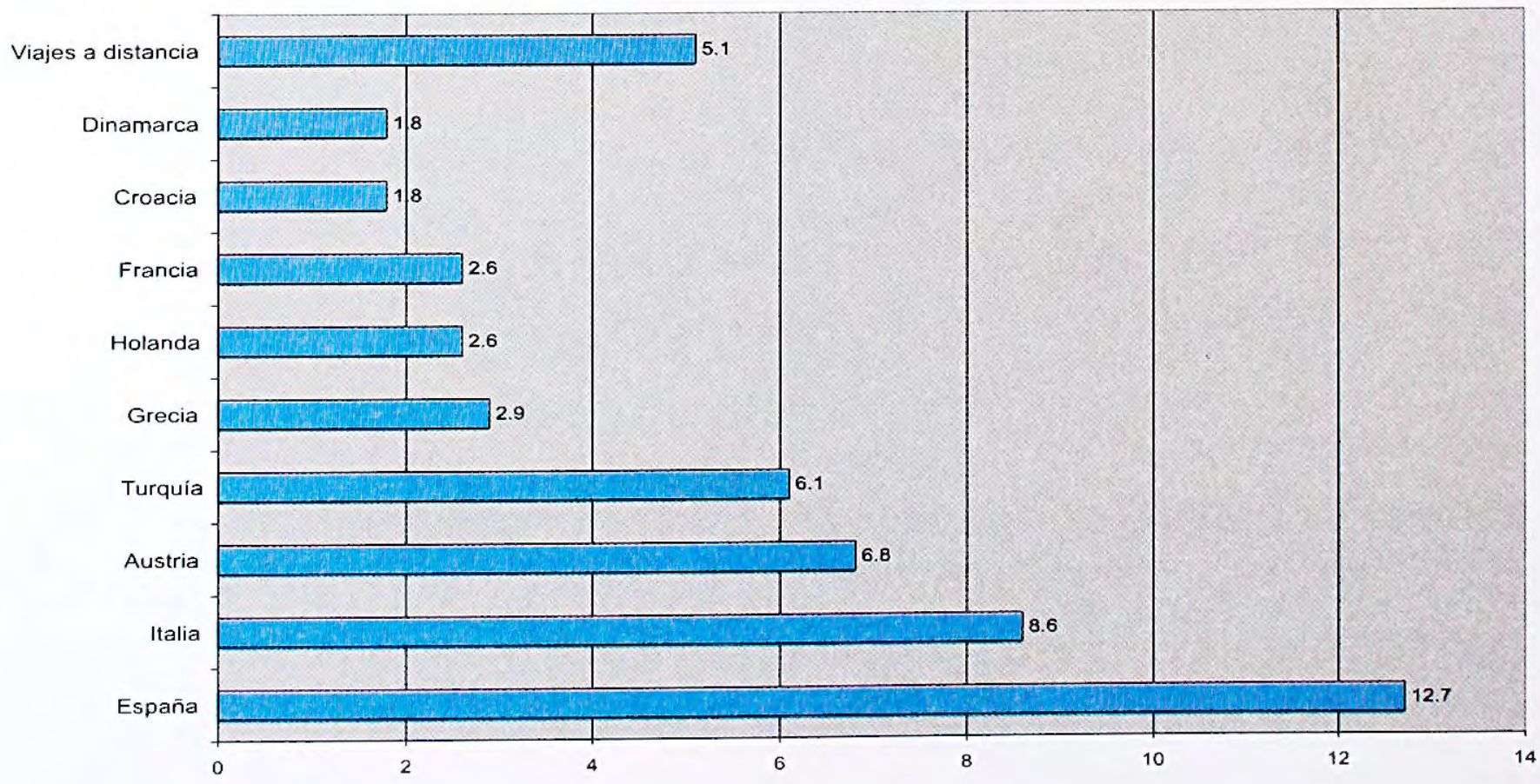


A continuación presentamos el resultado de una encuesta realizada por el Institut für Freizeit und Tourismusforschung del año 2000 aplicada a 1006 entrevistados.sobre la forma de como planifica sus vacaciones en función de la situación económica presente. ( Ver diagrama $\mathrm{N}^{\circ} 6$ )

El resultado es halagador pués aún cuando la seguridad económica no es de las más sólidas y las amenazas del terrorismo están siempre presentes, el mercado alemán de turismo presenta una cierta estabilidad. El ciudadano alemán no se amedrenta y continúa haciendo turismo.
El Instituto de Investigación de Turismo (F.U.R) realizó en noviembre del 2001 y en enero del 2002 una investigación sobre el impacto de los atentados del 11 de septiembre en los Estados Unidos (USA) sobre sus expectativas de turismo

El $70 \%$, en enero del 2002, manifestó que los ataques terroristas no influyeron en sus planes de turismo, mientras que el $30 \%$ dijo que "el recuerdo de septiembre" estuvo presente al momento de organizar sus vacaciones. (Ver cuadro $N^{\circ} 3$ )

\section{Diagrama $N^{\circ} 6$ Cómo planifica sus vacaciones en función del precio de la gasolina y del impuesto ecológico}

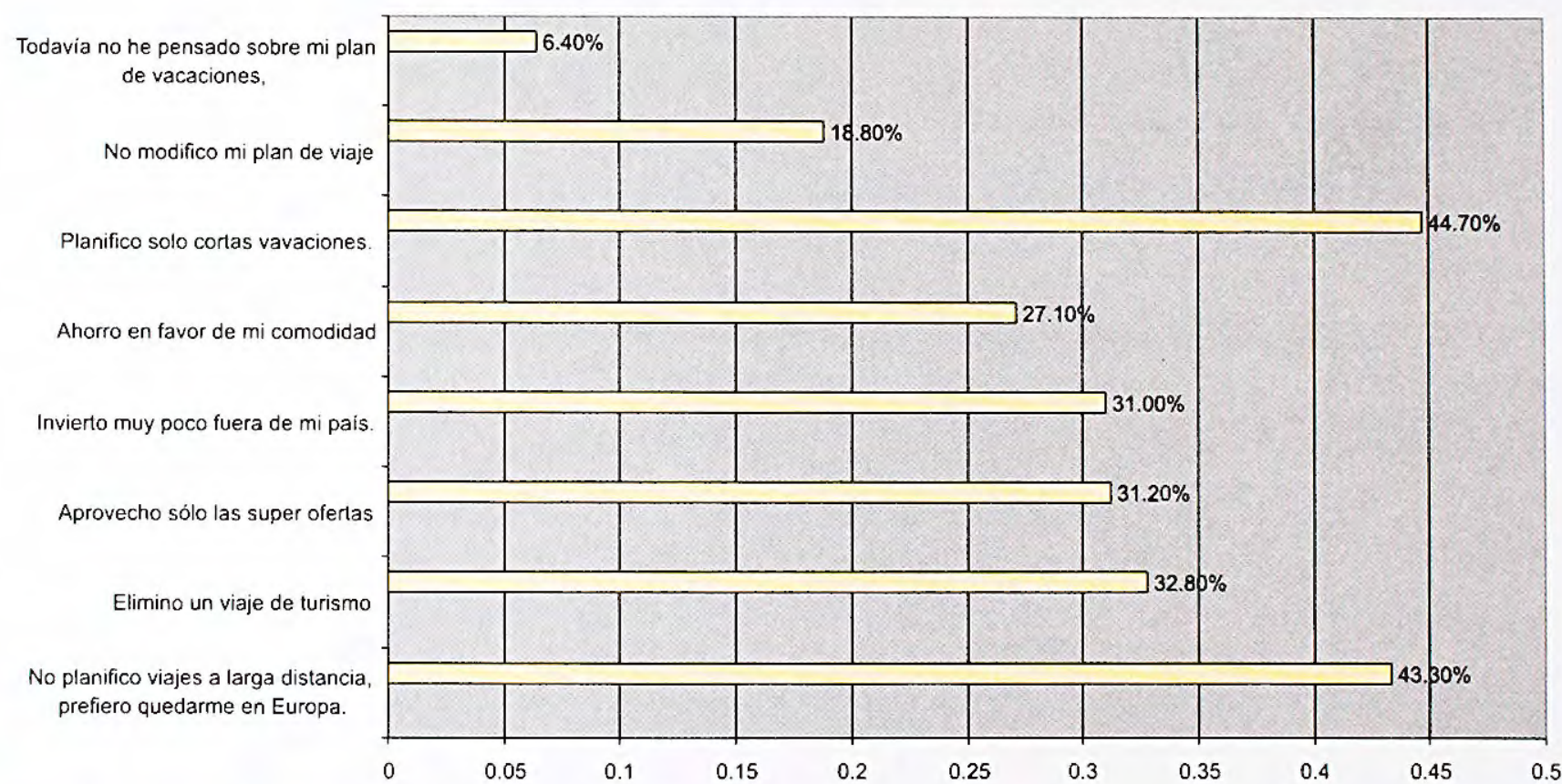

Fuente: Institut für Freizeit und Tourismusforschung. 2000

Cuadro $\mathrm{N}^{\circ} 3$

Impacto del ataque terrorista a los EE.UU en la planificación de las próximas vacaciones

\begin{tabular}{|lcc|}
\hline & Noviembre & Enero \\
Número de encuestados & 1000 & 1000 \\
Población adulta (millones) & $63,5 \%$ & $63,5 \%$ \\
No, no influye & $65 \%$ & $69 \%$ \\
Si. & $29 \%$ & $14 \%$ \\
No sé & $6 \%$ & $17 \%$ \\
Si + no sé & $35 \%$ & $31 \%$ \\
\hline
\end{tabular}


Aquellos que aceptaron alguna influencia en sus planes de turismo dieron las siguientes razones:

1. Reconsiderar los planes de vacaciones y esperar los acontecimientos a desarrollarse en la zona, la vuelta a la normalidad.

2. No realizar viajes en avión.

3. Evitar los vuelos a países islámicos.

4. Buscar países con clara estabilidad política y social.

5. Orientar el turismo hacia Alemania.

6. Orientar el turismo hacia los ya tradicionales países europeos, pero sin la utilización de medios de transporte aéreos.

Interesentante, según la investigación de la F.U.R, es notar que el sector de entrevistados, que manifestaron su deseo de no hacer turismo en los últimos dos meses (por razones de seguridad $u$ otros), subió porcentualmente su negativa de un $10 \%$ en noviembre a un $21 \%$ en enero.

Una evolución del interés de viaje 2001-2002 nos presenta el siguiente diagrama $\mathrm{N}^{\circ} 7$

\section{Diagrama N`7 Evolución del interés del viaje}

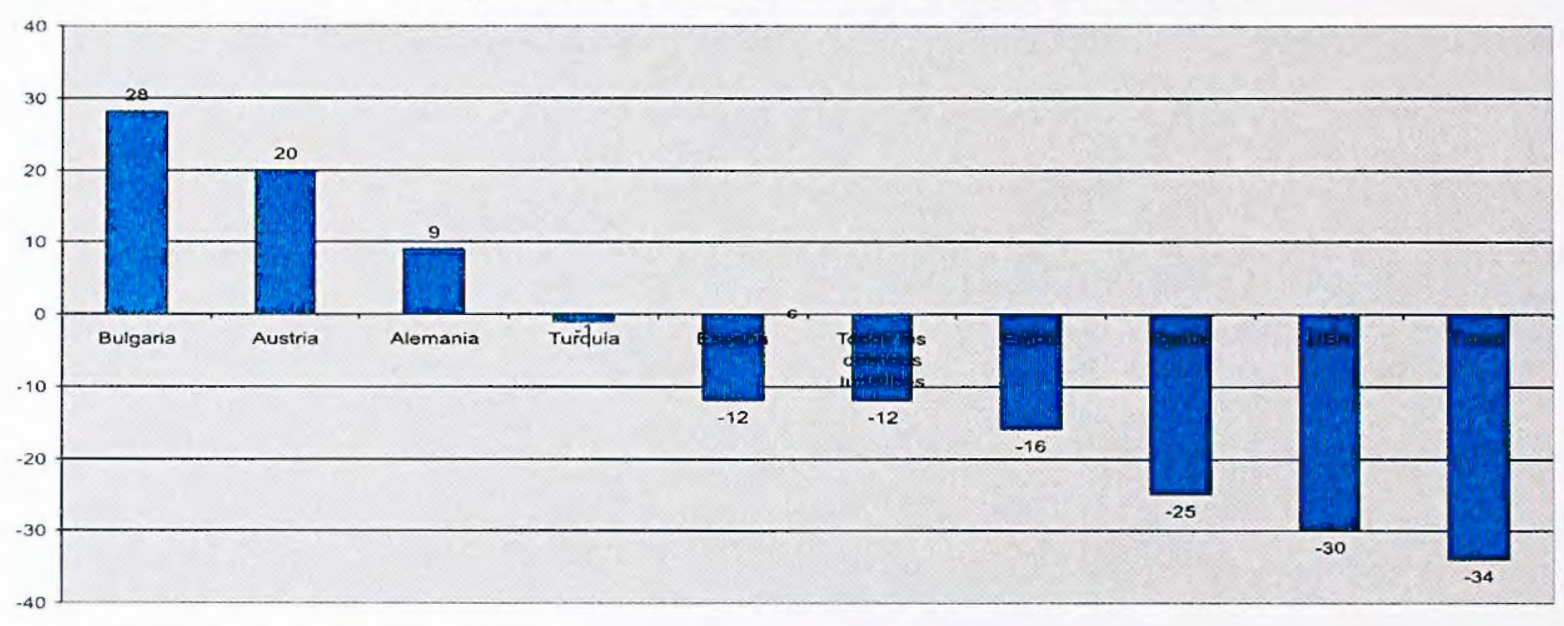

Fuente:Enero 2003 frente a Enero 2001

RA 2001 y 2003.

\subsection{Organización del viaje.}

Según Niederberghaus (2004) cientos miles de turistas alemanes se sientan luego de las vacaciones ante la computadora y dejan fluir sus pensamientos al aire. Las vacaciones son para los alemanes una cuestión que forma parte de su cotidaneidad. No en vano fue Alemania la primera nación en Europa que incorporó una legislación sobre los derechos de turismo en el Código Civil. Ninguna otra nación realiza más vacaciones en el mundo como los alemanes.

La lingüística muestra que hacer vacaciones tiene el mismo sentido que distracción, es decir tranquilidad o jubileo. Muchos abandonan sus ciudades en búsqueda de "lo maravilloso".

Según nuestra investigación (Ver diagrama $N^{\circ}$ 8) el
$44 \%$ planifica su viaje de turismo con una anticipación de 1 a 3 meses. Así puede organizar mejor su tiempo de trabajo y su economía.Un segundo grupo el $20 \%$ necesita de por lo menos 6 meses para la preparación del viaje, especialmente, si se trata de países bastantes distantes de Alemania. Un 14\% requiere sólo de 20 3 semanas previas, antes de salir de vacaciones. Estos últimos son los casos de las vacaciones "repetidas"que se realizan por segunda o tercera vez al mismo país de destino.Se cuenta con el conocimiento previo de precios, ofertas, lugares de visita y servicios. No hay una exhaustiva búsqueda de información previa al viaje.

Finalmente el $20 \%$ corresponde a los que no planifican las vacaciones, o simplemente no respondieron a la pregunta. 


\section{Diagrama $N^{\circ} 8$ Tiempo de planificación de viaje}

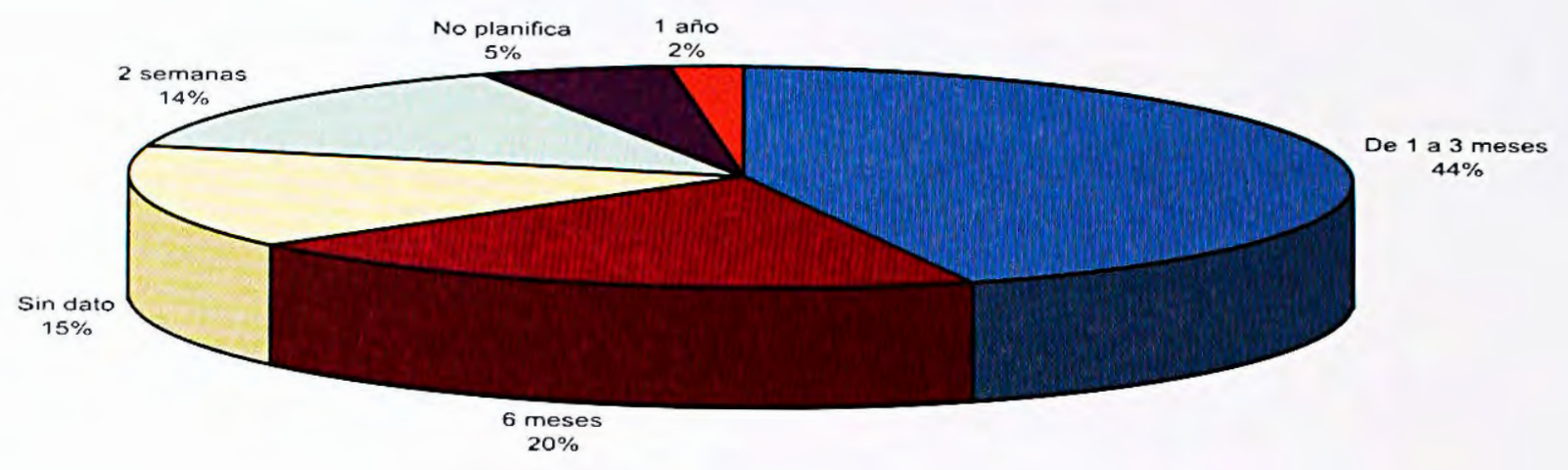

Por su parte,el R.A. N 34 del F.U.R. e.v reporta las siguientes estadísticas para los años 2000-2004. (Ver diagrama $\mathrm{N}^{\circ}$ 9)
La posibilidad de viaje a principio de año ha ido aumentando,mientras que tambien la seguridad de no hacer vacaciones ha disminuído. (Ver cuadro $\left.N^{\circ} 4\right)$

\section{Diagrama $\mathrm{N}^{\circ} 9$ Intención de viaje}

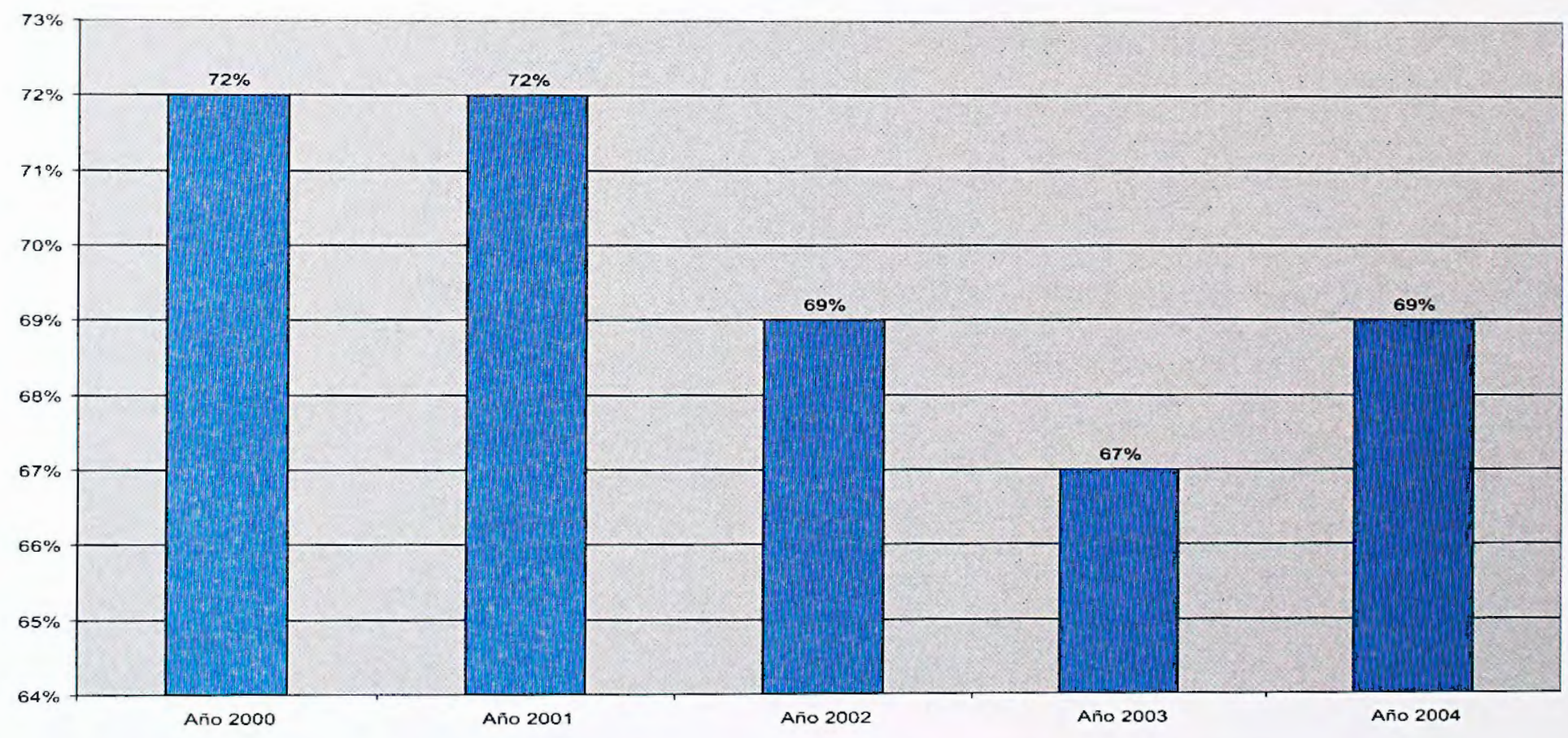

Fuente: FUR.R.A. 2004. 


\section{Cuadro $\mathrm{N}^{\circ} 4$}

\begin{tabular}{|lcccc|}
\hline \multicolumn{4}{c}{ R.A. 2004. Intención de viaje en el mes de enero } \\
\hline $\begin{array}{l}\text { Pobl.(Mayor de 14) } \\
\begin{array}{l}\text { Si, probablemente } \\
\text { haga turismo }\end{array}\end{array}$ & 1995 & 1999 & 2003 & 2004 \\
No sé todavía & $72 \%$ & $71 \%$ & $67 \%$ & $69 \%$ \\
$\begin{array}{l}\text { No, probablemente } \\
\text { no haga turismo }\end{array}$ & $13 \%$ & $14 \%$ & $17 \%$ & $18 \%$ \\
\hline
\end{tabular}

La planificación del viaje depende de los intereses de los turistas como de las imágenes que proyecte el destino turístico. Los turistas siempre demandan un destino turístico, que, cuando no existe es artificialmente creado siguiendo modas, corrientes, y avances tecnológicos.

Por otro lado, el individuo como tal pasa por grandes y pequeños cambios a lo largo de su vida, ajustes en lo personal, social y psicológico antes de ser turista.

El ser turista según (Santana,1997) demanda por lo menos el cumplimiento de cinco dimensiones

Proceso de decisión

Preparación del viaje.

Desarrollo o realización del viaje.

Proceso de cambio

Conversión del sujeto en valor de cambio.

Retorno a la sociedad de origen.

El potencial turista cumple con una serie de requisitos para llegar a serlo. Primero, tiene un conjunto de expectativas sobre lugares, actividades y culturas producto de su contacto con otras personas, familiares y conocidos y de las campañas publicitarias preparadas por las agencias de turismo,o instituciones estatales.

Posteriormente, busca de información a través de internet o de la visita personalizada a las agencias de viajes. Esta información incluye precios, ofertas de servicios y seguridad en el país de destino turístico.

La tercera fase, la más importante, supone un abandono de la cotidianidad y separación de sus semejantes que siguen realizando las mismas actividades antes realizadas por él. Se da una ruptura con el mundo doméstico anterior,y se cruza la frontera real física y geográfica en el otro país o destino turístico. Se cumplen con los trámites burocráticos que exigen el país receptor y empieza un predominio de lo turístico (ocio, descanso, aventura, descubrimiento, tranquilidad y recreación) sobre lo rutinario.

De ahí que, también por parte de las instituciones turísticas peruanas se deba organizar campañas de promoción turística con la suficiente antelación en Alemania. Una fuerte ofensiva turística durante los meses de enero a marzo, fecha,en que según la encuesta, los alemanes empiezan a preparar sus vacaciones de verano de junio-setiembre, sería muy positiva. La oferta turística reforzaría los atractivos culturales e históricos de nuestra cultura peruana.

La Feria Internacional el Turismo (I.T.B.) realizada anualmente en el mes de marzo es una muy buena puerta de entrada a la promoción turística en Alemania, pero que debe mantenerse en el ámbito público con una presencia constante, a fín de 
figurar nuestro país como posible destino turístico.

Según los datos de la Reiseanalyse R.A. 2004 para el año 2003, el $44 \%$ prefirió reservar los llamados "paquetes turísticos" en las agencias de viajes.Sin embargo se puede observar una gran diferencia entre los viajes nacionales e internacionales.EI $58 \%$ de los viajes y actividades en el extranjero están organizados a través de una agencia de viajes mientras que los viajes nacionales sólo el $17 \%$.

La duración del viaje de vacaciones en los últimos años ha continuado descendiendo y para el 2003 fue de un promedio de 12,8 días.(Ver diagrama $N^{\circ}$ 10)

\section{Diagrama №10 Promedio de días de vacaciones}

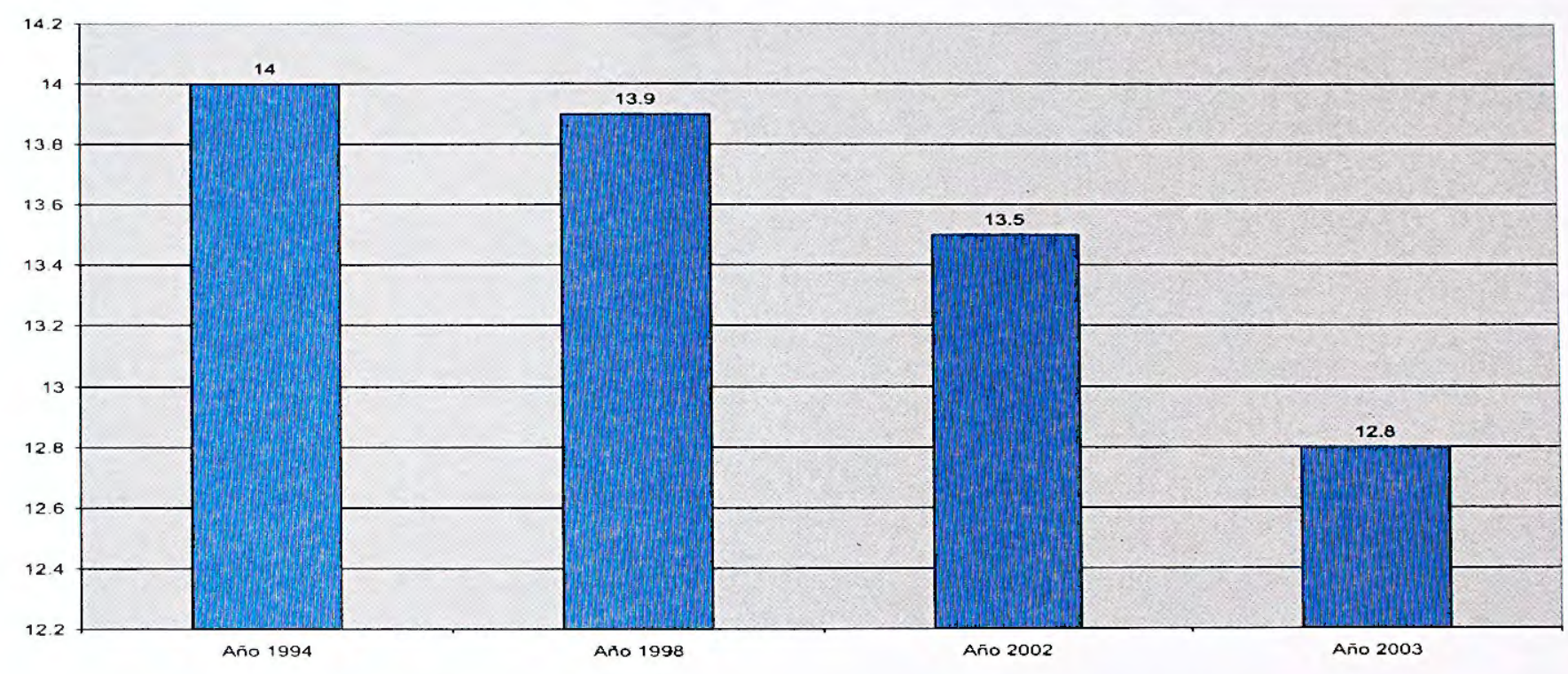

La inversión diaria durante el viaje de turismo ha aumentado. En el 2003 los turistas alemanes gastaron 62 euros por día, es decir, 10 euros más que en 1996.
A continuación presentamos algunas estadísticas sobre los medios de transporte, organización, gastos y duración del viaje del turista tanto al interior como al exterior del país. (Ver cuadro $\mathrm{N}^{\circ} 5$ ) 


\section{Cuadro $\mathrm{N}^{\circ} 5$}

\begin{tabular}{|c|c|c|c|c|}
\hline & R.A 2004 & & Turismo 2003 & \\
\hline Turismo $100 \%$ & 1994 & & 2003 & \\
\hline Transporte & Total & Total & Nacio & Intem. \\
\hline Auto, vivienda móbil & 51,9 & 49,2 & 74,7 & 36,9 \\
\hline Avión & 26,5 & 32,3 & 0,5 & 57,7 \\
\hline Autobus & 10,8 & 10,3 & 10,5 & 10,3 \\
\hline Tren & 8,6 & 6,1 & 12,8 & 2,9 \\
\hline \multicolumn{5}{|l|}{ Organización } \\
\hline $\begin{array}{l}\text { Paquete Turistico } \\
\text { reserva en agencia }\end{array}$ & 25,0 & 29,0 & 8,9 & 38,7 \\
\hline de viajes & 18,0 & 15,1 & 7,6 & 18,8 \\
\hline $\begin{array}{l}\text { Reserva directa en } \\
\text { hoteles, pensiones }\end{array}$ & 32,0 & 27,7 & 36,8 & 23,4 \\
\hline Gastos de viaje & - & 789 & 525 & 917 \\
\hline $\begin{array}{l}\text { Duración de viaje } \\
\text { (dias) }\end{array}$ & 14 & 12,8 & 11,0 & 13,7 \\
\hline Turistas (millones) & 67,2 & 66,1 & 21,4 & 44,6 \\
\hline
\end{tabular}

Regresando a los datos de nuestra encuesta sobre la modalidad de viaje del turista alemán tenemos los siguientes resultados (Ver diagrama $N^{\circ} 11$ )

El $43 \%$ prefiere viajar por su cuenta, sin la mediación de alguna agencia de viajes. El turista mismo organiza su viaje de vacaciones: Busca la información básicamente en internet, realiza los contactos necesarios, hace las reservaciones requeridas para su permanencia en el destino turístico, averigua las posibles extensiones turísticas y elije y reserva las líneas aéreas de transporte.

Este tipo de turista manifiesta que tiene más libertad de decisión y acción. Está más cercano y abierto a "entender" las múltiples opciones de viaje que se vayan presentando en el camino. Muchos entrevistados manifestaron: "al visitar otro país lo más importante es gozar de libertad y no de imposiciones".

Estos viajes, por lo general, duran entre dos o tres semanas y son realizados por gente relativamente joven.
Los que manifestaron preferir una agencia de viajes fueron el $32 \%$. Suelen viajar a destinos un tanto más alejados y son personas mayores que desean contar con mayor seguridad y respaldo infraestructural en el país visitado.

Un $19 \%$ afirmó que utiliza las dos anteriores modalidades.El billete de vuelo llamado "principal" a través de la agencia de viajes en Alemania y los vuelos menores u optativos en el país destino. El hospedaje inicial de llegada es reservado nuevamente a través de la agencia de viajes, con la opción de tomar más reservas, hoteles y traslados por cuenta del viajero.

Una imagen sobre los paquetes turísticos y los viajes organizados individualmente nos la ofrece el Reiseanalyse RA. 2004.F.U.R.e.v.

Los paquetes turísticos aún cuando lo tienen todo organizado tienen la desventaja sobre la credibilidad y confianza del cumplimiento de los servicios ofrecidos, que se convierten en retos para los organizadores, a fin de conseguir más clientes. (Ver cuadro $N^{\circ} 6$ ) 


\section{Diagrama №11 Modalidad de viaje}

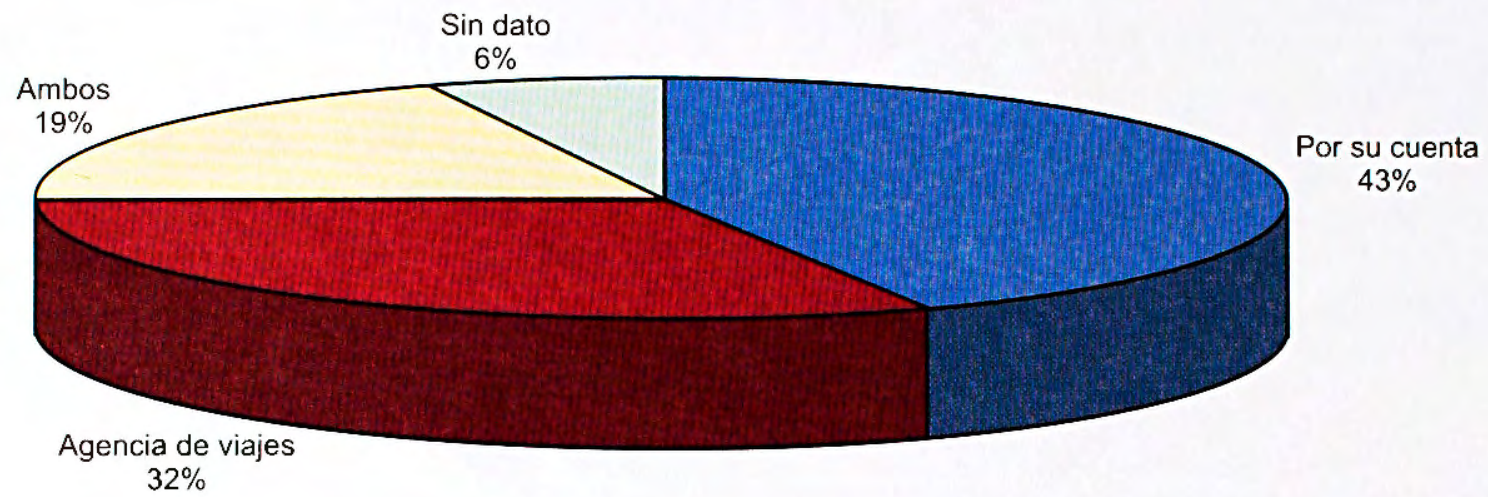

Cuadro $\mathrm{N}^{\circ} 6$

Opiniones sobre los paquetes turísticos

\begin{tabular}{|lcc|}
\hline Los paquetes son:... & Paquete & Individual \\
\hline $\begin{array}{l}\text {...viajes preparados sin compli } \\
\text { caciones y sin preparación por } \\
\text { parte del viajero }\end{array}$ & 90 & 65 \\
$\begin{array}{l}\text {...esencialmente más baratos } \\
\text { que los viajes individuales }\end{array}$ & 63 & 41 \\
$\begin{array}{l}\text {...dejan muy poco tiempo libre } \\
\text { y son muy ajustados a un horario } \\
\text { fijo. } \\
\text {....precios más baratos }\end{array}$ & 17 & 48 \\
\hline
\end{tabular}


La relación entre gastos por turismo y calidad del servicio ha sido también investigado por el Reiseanalyse 2004. F.U.R. ev. Los datos que presentamos a continuación nos dan más de una idea de las expectativas del turista alemán.Son dos los polos entre los que gira su demanda "lujo sin reducción de gastos" y "lo más barato posible". (Ver gráfico $\left.\mathrm{N}^{\circ} 1\right)$

Algunas de las declaraciones refieren:

"Vacaciones a buenos precios, por supuesto.....pero no en desmedro de la calidad."
"Aprovechamos las grandes ofertas......pero no somos un pueblo en la miseria."

\section{Motivación en la elección del destino turístico.}

Las estadísticas del Reiseanlyse 34 del 2004 nos muestran, para el 2003, una relativa estabilidad de viaje A pesar de la inseguridad económica y del latente peligro terrorista, el turista alemán no deja de disfrutar de sus vacaciones.

En el diagrama $N^{\circ}$ 12: Motivo de viaje de turismo para los alemanes, podemos observar:

\section{Gráfico N ${ }^{\circ} 1$ \\ Precio y calidad de los viajes de turismo}

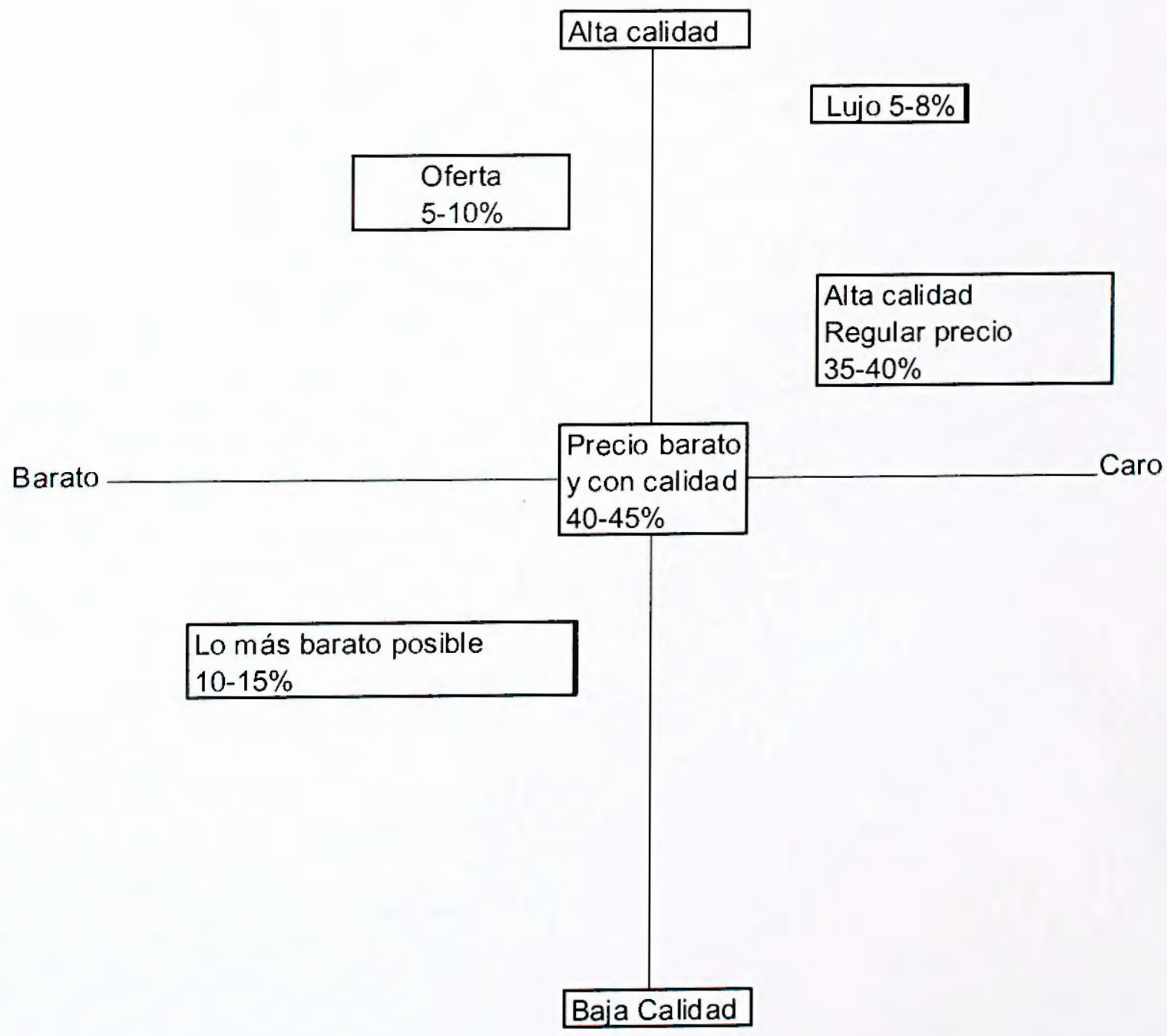




\section{Diagrama $\mathrm{N}^{\circ} 12$ Motivo de Turismo para los alemanes}

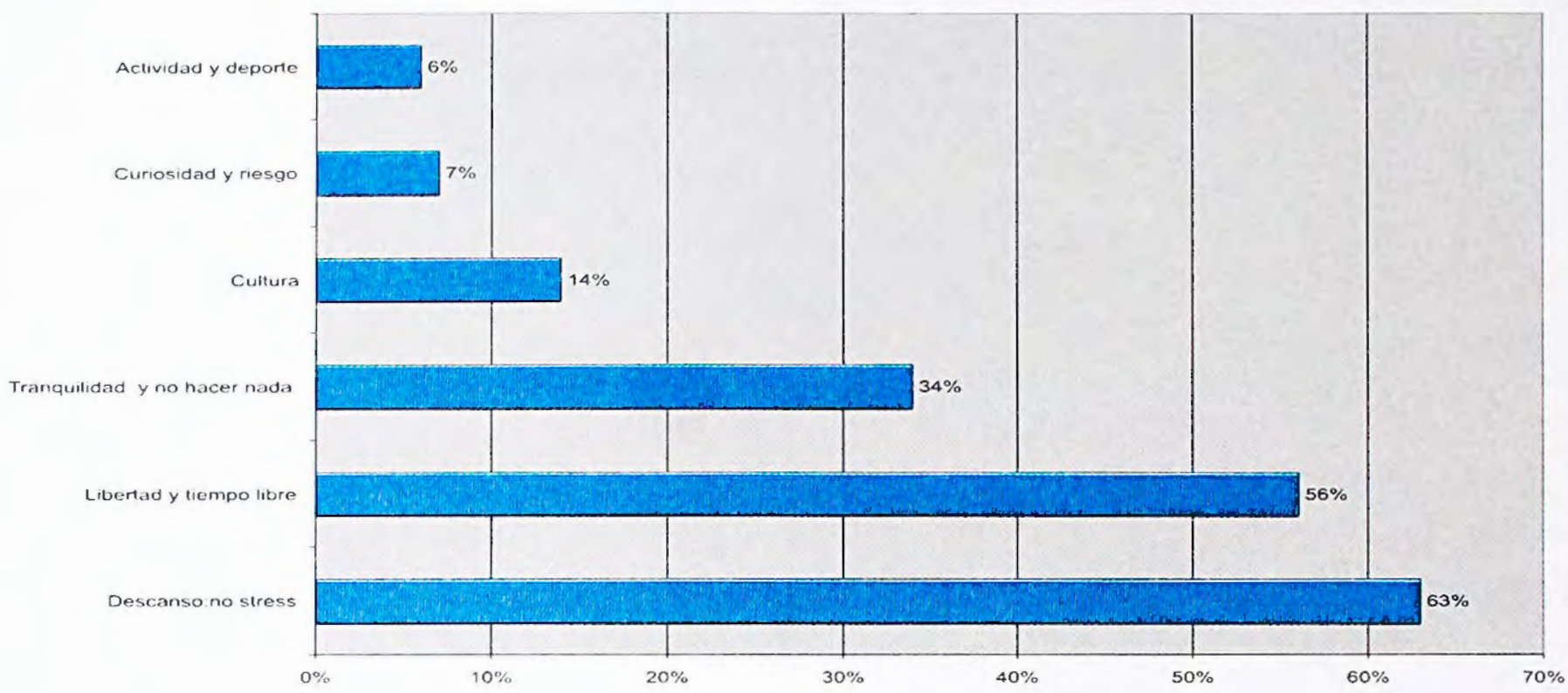

Según el F.U.R, 2003 la tercera edad será el motor de crecimiento del turismo en el futuro. En el 2001 fueron mas de 12 millones de alemanes mayores de 60 años los que hicieron turismo. Segun las proyecciones llevadas a cabo por la misma institución en los próximos 20 años, más del $80 \%$ de las personas de la tercera edad realizará por lo menos una vez al año turismo.( Aderhold, P. 2002). Hoy, refiere el mismo autor, el porcentaje alcanza el $67 \%$.Este grupo objetivo tiene más la posibilidad y la probabilidad de desarrollar diferentes actividades en sus vacaciones que otros grupos objetivos.

Para el Pressetext 2001 del F.U.R elaborado por Lohmann y Danielsson (2003) otro de los sueños del alemán son "las vacaciones en la nieve",es decir, las vacaciones de invierno en el sol“. Un 14\% de los vacacionistas durante 5 días o más gustan pasar sus vacaciones de noviembre a marzo en el sol. De ellos el $28 \%$ prefiere el Mediterraneo, el 23 $\%$ los Alpes y el $6 \%$ las zonas altas de Alemania. Para mantenerse en actividad optan por diversas alternativas. Un $15 \%$ de los turistas puede ser denominado como turistas en busqueda de la tranquilidad. El $11 \%$ de los turistas de invierno son definidos como turistas de aventura, el 15\% amantes de la naturaleza y el $4 \%$ como amantes de las fiestas. Los motivos de viaje por salud revelan el $4 \%$ y los motivos culturales reducidos al pequeño segmento del $2 \%$.

Una encuesta realizada por el F.U.R y el NIT (2003) a los turistas alemanes sobre el significado de un turismo cultural dió los siguientes datos. (Ver cuadro $\mathrm{N}^{\circ} 7$ )

Pero, también el turismo cultural significaría en relación con los otros tipos de turismo. (Ver diagrama $N^{\circ} 13$ ) 


\section{Cuadro $\mathrm{N}^{\circ} 7$ \\ ¿Qué es el turismo alemán?}

\section{¿Qué es el Turismo cultural?}

1. Referido a la historia, su ubicación y restos Materiales.

2. Visita a los museos y exposiciones

3. Viaje en grupos con un plan establecido y

Un guia turistico

4. Actividades culturales (teatro, musicales, y conciertos)

5. Disfrute de la cultura actual y su filosofia.

\section{Diagrama $\mathrm{N}^{\circ} 13$ Otros significados de turismo cultural}

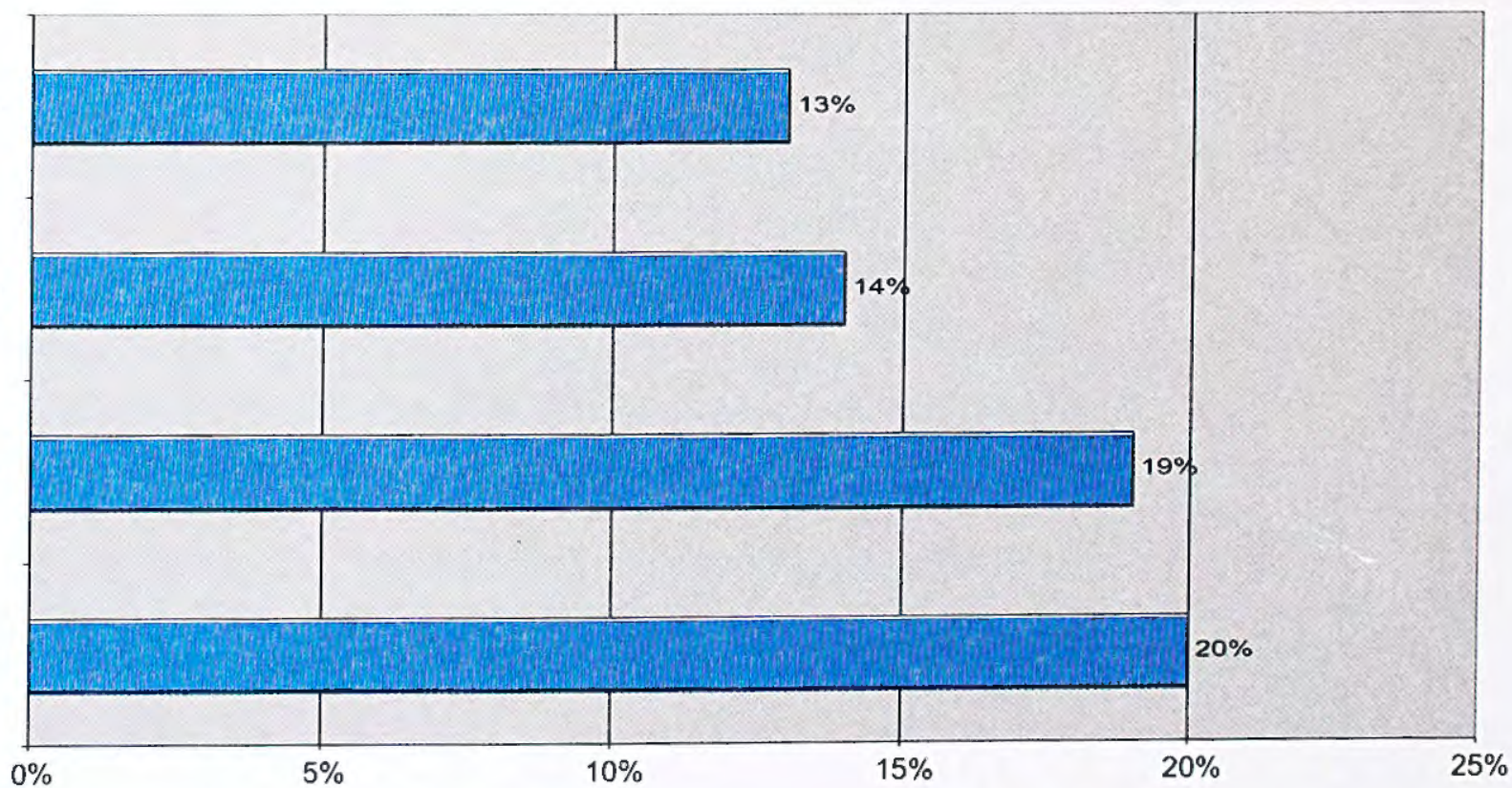


Para el $10 \%$ de los turistas de invierno la visita a los parientes y amigos es una buena ocación para hacer turismo en época de invierno.El 24 de diciembre es una fecha propicia para el comienzo de las vacaciones.

El deporte en las vacaciones ocupa otro sector importante entre las preferencias de los alemanes. Como ellos mismos manifiestan "el movimiento corresponde a las vacaciones".

Según la valoración hecha por el R.A. del FUR. (2004), el $77 \%$ prefiere hacer caminatas durante sus vacaciones, el $71 \%$ opta por tomar baños y el $41 \%$ hace ciclismo. Este grupo de turistas deportivos no es grande pero, siempre diferenciado de los otros. Siempre fue dominio de los más jóvenes, pero últimamente,el sector de la tercera edad incorpora este tipo de turismo dentro de sus requerimientos. El porcentaje de este último sector (mayores de 60 años) ha aumentado en sólo 5 años del $8 \%$ al $16 \%$.

Sin embargo, más valor que el turista deportivo lo tiene la tranquilidad en el turismo con un $79 \%$ y el total descanso con el $31 \%$.

Las preferencias del turismo, según las mujeres y hombres se presentan como la mayor posibilidad de reencuentro con la pareja, "la oportunidad de estar juntos"

El principal motivo para hacer turismo, sin distinción de sexos, es el disfrute y la tranquilidad. El $59 \%$ afirma que, la libertad y el deseo de tener tiempo libre es una de las principales causas en la elección de las vacaciones. El $45 \%$ refiere que, el disfrute en conjunto, en pareja, de buen clima y sol, es otra de las motivaciones.El R.A. para el 2001 en su investigación encontró que los hombres aman el deporte activo en un $9 \%$ mientras que las mujeres sólo en un $5 \%$.Frente al riesgo los hombres lo prefieren en un $9 \%$ y las mujeres en un $6 \%$.

Por el contrario, en el turismo por salud, las mujeres estan representadas por el $32 \%$ y los hombres por el $27 \%$. Así también en el turismo estético y de belleza las mujeres alcanzan el 19\% mientras que los hombres el $12 \%$. El grupo que viaja por cuestiones eróticas o de flirt no es tan diferenciado entre hombres y mujeres. Los hombres representan el $10 \%$ y las mujeres el $7 \%$.

La planificación de un turismo de campamento está a cargo de los hombres, sólo un $6 \%$ de las mujeres invierten sus esfuerzos en esta actividad. En cambio, unas vacaciones de wellness o fitness para las mujeres representa el $10 \%$ y para los hombres el $8 \%$.

Lo que si es coincidente tanto para hombres como para mujeres es el destino turístico y ambos sectores señalan países como Alemania, España, e Italia en la lista de opciones de viaje.

La preferencia por Italia ha ido en aumento.En el periodo 2001-2003 se planificaron unos 18 millones de potenciales turistas. En enero de 1995 fueron 11 millones los entusiasmados por realizar un viaje a Italia.La competencia de Italia como un destino turístico internacional se hace día a día más notoria. (Ver cuadro $\mathrm{N}^{\circ} 8$ )

\section{Cuadro $\mathrm{N}^{\circ} 8$ \\ Turismo Alemán a Italia}

\begin{tabular}{|lcc|}
\hline \multicolumn{3}{|c|}{ Alemanes que en los próximos 3 años probablemente viajen a Italia } \\
\hline Enero 1995 & Enero 1998 & Enero 2001 \\
$17 \%$ & $25,6 \%$ & $28,41 \%$ \\
\hline
\end{tabular}


La multiplicidad de ofertas, como son los mares de la costa, o el, pasado histórico son premisas de innovación de una promoción turística que deben ser muy bien trabajadas por las organizaciones peruanas, ya que por sí solas no son garantía de éxito.
Los resultados de nuestra investigación nos dan algunos resultados de la motivación de viaje del turista alemán al extranjero. (Ver diagrama $\mathrm{N}^{\circ} 14$ )

\section{Diagrama №14 Motivación de viaje del turista alemán al extranjero}

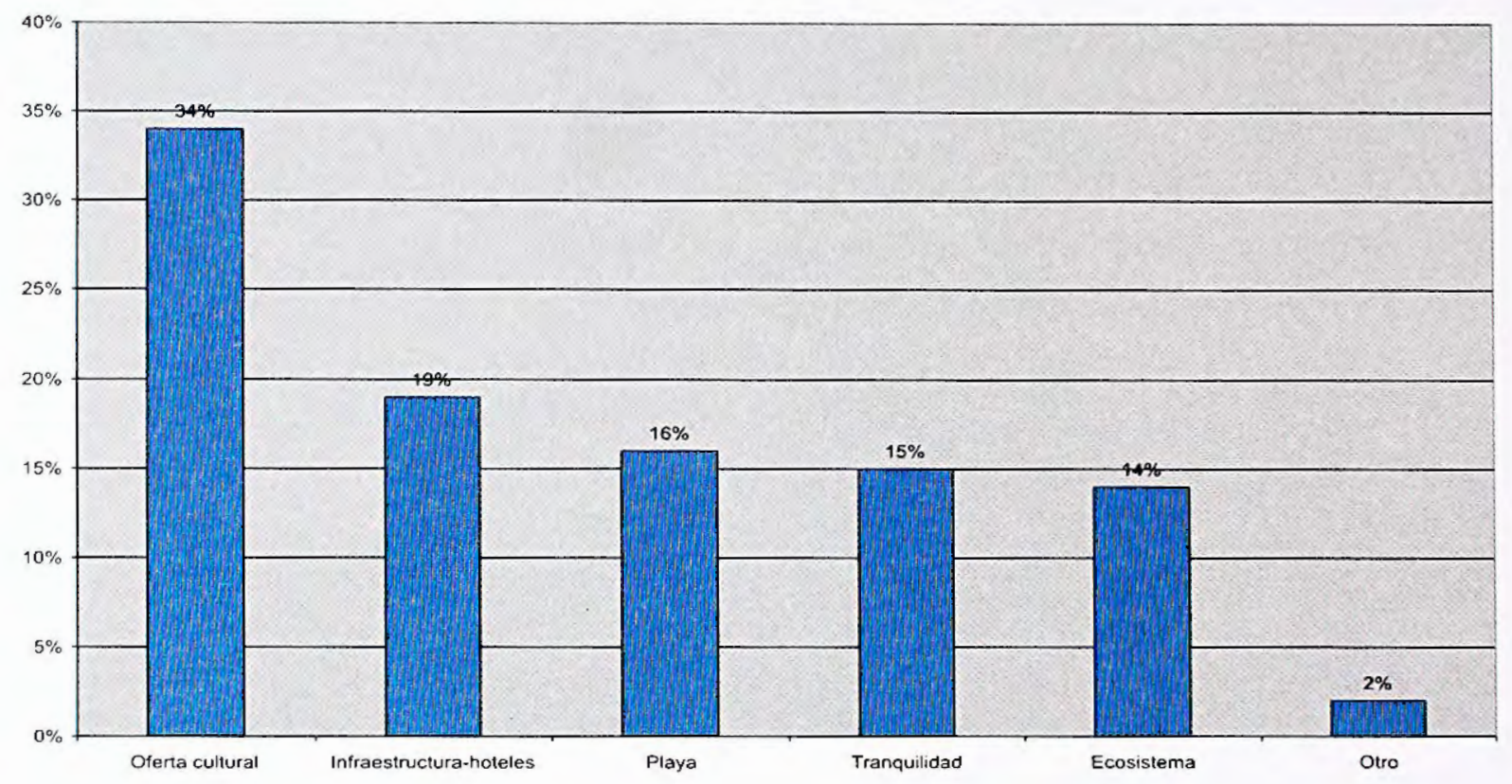

La oferta cultural con el $34 \%$ es la segunda motivación de viaje para el turista alemán.Pero aún cuando el porcentaje es bastante representativo en la tabla de análisis, en relación a las otras variables, es sólo la tercera parte del total.

Cuando agrupamos las categorías playa, tranquilidad, y ecosistema tenemos el $43 \%$ que representa en conjunto la primera alternativa de viaje.Este grupo manifiesta que frente al estrés $y$ trabajo diario unas verdaderas vacaciones no deben incluir preocupaciones ni problemas.

En la playa sinónimo de sol, arena y placer debe reinar la tranquilidad y el sosiego. Un buen ecosistema con el disfrute de las ofertas de la naturaleza y quizás unido, para los jóvenes , a un turismo de aventura es otra de las buenas alternativas para el turismo.

Pero para que este turismo se realice con las óptimas condiciones, el turista requiere de una seguridad en la infraestructura hotelera y en los servicios. No en vano, los viajes de turismo a larga distancia incluyen en sus ofertas "paquetes establecidos" desde el alojamiento hasta el último zumo de naranja. Además de ser desde el punto de vista económico mas sugerentes.

El 19\% mencionó como condición necesaria para el viaje la existencia de una infraestructura en el país de destino más o menos aceptable.

\section{Presencia de Alemania en América Latina}

En este acápite tenemos pocos puntos de confrontación con las investigaciones realizadas en Alemania por el F.U.R.

En el resultado de las investigaciones, América Latina no figura en sí misma como posible destino turístico . Como ya se vió en el cuadro $\mathrm{N}^{\circ} 2$, los 
viajes a larga distancia podrían incluir los países latinoamericanos, aunque con cierto cuidado, frente a los países centroamericanos que si tienen una buena presencia para el turista alemán.

Del total de nuestros entrevistados (Ver diagrama $\left.N^{\circ} 15\right)$, el $60 \%$ visitó alguna vez algún país de América Latina. América Central ocupa con el $23 \%$ el primer lugar de las preferencias .Los países más visitados son República Dominicana, Cuba y las Islas Margaritas en Venezuela. Sigue en términos porcentuales Chile, Argentina y Uruguay con el $20 \%$. Estas regiones son visitadas, entre otras razones, por las vinculaciónes políticas tempranas entre Europa y América Latina, por las inmigraciones europeas a la Argentina, Chile y Uruguay, y por la oferta de paquetes turísticos que ofrecen una visita conjunta a estos países.

El Perú con el $20 \%$ representaría la tercera opción de viaje, unido a un desplazamiento turístico por el norte al Ecuador y /o por el sur a través del Lago Titicaca a Bolivia. Además estos tres países de la región andina, también ofrecen un circuito turístico en conjunto.

Desde el punto de vista cultural, Perú ofrece la marca de "país de los Incas" cuna de una de las civilizaciones más antiguas del mundo, pero que no representa por si sola un foco de atracción turística. Son pocos los interesados o especializados en viajar al Perú por fines estrictamente culturales o históricos. Este tipo de turismo, más bien, se realiza paralela al desempeño de otra actividad, sea congresos internacionales, visitas de negocios o inversiones por parte de empresas extranjeras.
En los últimos años existe una demanda relativamente grande de turistas que aprovechan su estadía en el Perú para el aprendizaje del castellano, sobre todo en el Cusco. Estos cursos se complementan con talleres de cocina, danza, teatro, literarios e históricos.

Entonces, debemos pensar que la atracción cultural del Perú como "ciudad perdida" de los Incas, es cuestión de análisis y reinterpretación. No por la falta de valor como patrimonio cultural de la humanidad, sino por desconocimiento y falta de interés para el ciudadano alemán. La búsqueda de tranquilidad y la huída al estrés son los principales requerimientos del turista.

El porcentaje del $20 \%$ de los turistas que viajan para el Perú, incluye también al alemán que por motivos familiares o amicales viaja al Perú y no precisamente movido por fines históricoculturales.

El $14 \%$ de los turistas que viajaron a Bolivia o Ecuador incluyen también en su itinerario la visita a otro país andino.La motivación, nuevamente, no es el turismo aislado a un sólo país, sino la visita conjunta de por lo menos 2 o 3 países. Las causas de esta preferencia son evidentes. Primero, el costo económico, segundo la distancia con Europa y finalmente, el deseo de conocer cuanto más se pueda y mejor a un precio cómodo.

México con el $14 \%$ representa una atractiva alternativa para el turista alemán. En tanto que Brasil, Venezuela, Colombia y Paraguay registran el $8 \%$ en la tabla de preferencias. 


\section{Diagrama $\mathrm{N}^{\circ} 15$ Países de América Latina visitado por los turistas alemanes}

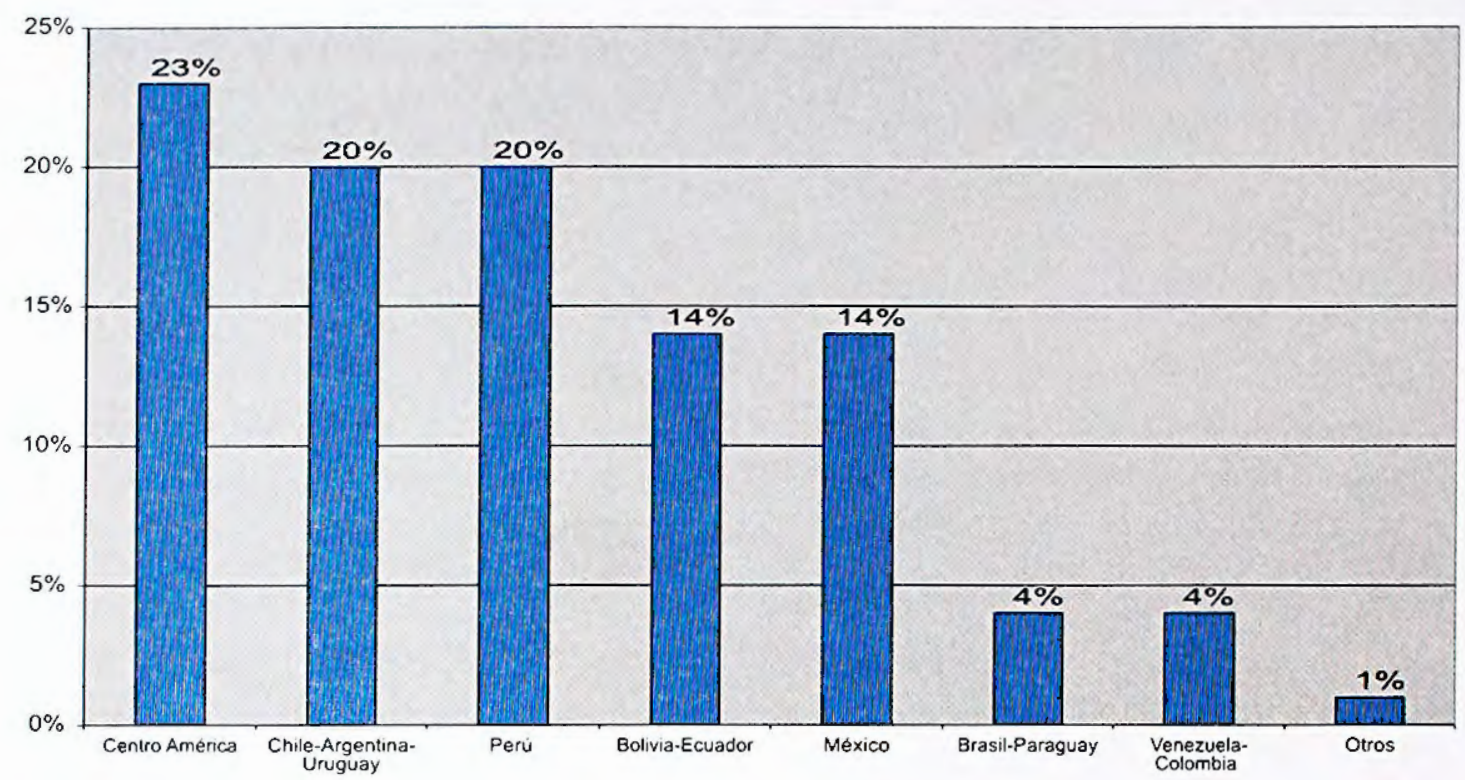

\section{El Perú como posibilidad de destino turístico.}

El $42 \%$ del $63 \%$ de los turistas alemanes que no estuvieron en el Perú manifestó su deseo de hacerlo alguna vez.

El $17 \%$ expresó categóricamente su negativa de viaje al Perú y un sorprendente $41 \%$ demostró indiferencia a la pregunta, con la ausencia de respuesta.

La elección del destino turístico peruano es una decisión indirecta. El turista alemán al plantearse la posibilidad de hacer turismo cultural no piensa en el Perú como posibilidad inmediata de viaje, sino se plantea el análisis en sentido contrario. Al respecto los comentarios de algunos turistas nos ilustran mejor el caso.

" si voy a Sudamérica, por ejemplo al Perú o Bolivia, me gustaría por supuesto conocer su historia."

"ya que tengo un viaje tan largo y costoso tengo que ver y visitar todo lo que puedo no?".

"si tuviera alguna persona conocida o amigos en el Perú o Sudamérica, me gustaría viajar allá.....pero también es muy caro todo no?.."

De las declaraciones anteriores inferimos que la motivación de un eventual viaje al Perú no es la búsqueda de tranquilidad o el escape al estrés cotidiano, con el disfrute de las playas y centros de veraneo, sino otros. Nuevamente, el problema radica en el simple desconocimiento de la riqueza peruana, fuera de sus límites nacionales. Un programa de marketing y de promoción de lo peruano llegando al grupo objetivo permeable a un turismo peruano se hace seriamente necesario. Existe una apertura del turista alemán a lo nuevo, que debe ser canalizado y aprovechado .

Si vemos el diagrama $N^{\circ} 16$, observamos que el $50 \%$, la mitad de los posibles turistas al Perú,luego de un previo conocimiento e información sobre el país,estaría dispuesto a viajar por motivos culturales y ecológicos. La curiosidad y las ganas de conocer gente con el $28 \%$ ocupa la segunda posición, lo que demuestra esa apertura hacia lo nuevo y "exótico" como fue definido por algunos de los entrevistados.

El $11 \%$ demandó la presencia de familiares y amigos como la condición para realizar un viaje al Perú. Algunos mencionaron:

"siempre es bueno tener algún punto de referencia en el país que visitas ...puede ocurrir algún accidente o percance.." 
El $8 \%$ corresponde de nuestros entrevistados coresponde al grupo de los académicos que por fines profesionales estarían dispuestos a viajar al
Perú. Sólo el $3 \%$ indicó el Perú como posible destino turístico para la realización específica de vacaciones.

\section{Diagrama №16 Motivación de un eventual viaje al Perú}

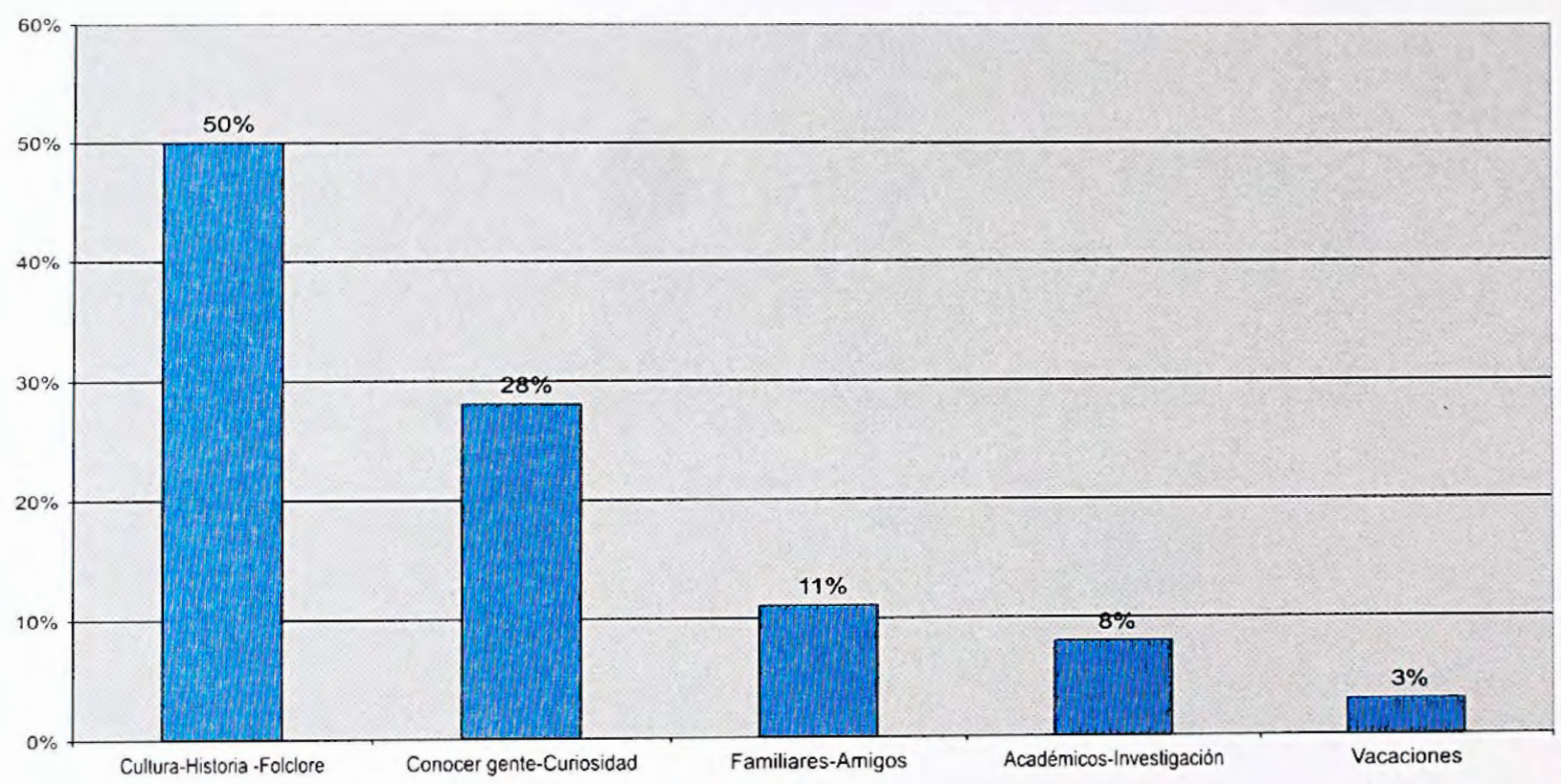

\subsection{El Perú como destino turístico.}

A la pregunta de ¿Estuvo en el Perú? respondió el $21 \%$ afirmativamente, el $63 \%$ nunca estuvo en el Perú y el $16 \%$ no contestó.

Los motivos de viaje, en comparación con las motivaciones eventuales de turismo, difieren significativamente.(Ver diagrama $\left.N^{\circ} 17\right)$

La principal causa de un viaje al Perú son los motivos familiares y las redes de amigos en el país de destino con el $31 \%$. La finalidad del viaje es muy clara: "se viaja al Perú porque hay que visitar a la familia". Estos desplazamientos son más frecuentes a fines de año por las festividades de Navidad. Además, este porcentaje aumenta con el $26 \%$ de los encuestados que manifestaron paralelamente también su deseo de hacer vacaciones en el Perú

Existe una correspondencia de motivaciones entre los que viajan por vacaciones y los que viajan por visitar a la familia, porque el que viaja con o por la familia, lo hace en periodo de vacaciones. 


\section{Diagrama N¹7 Motivación real de un viaje al Perú}

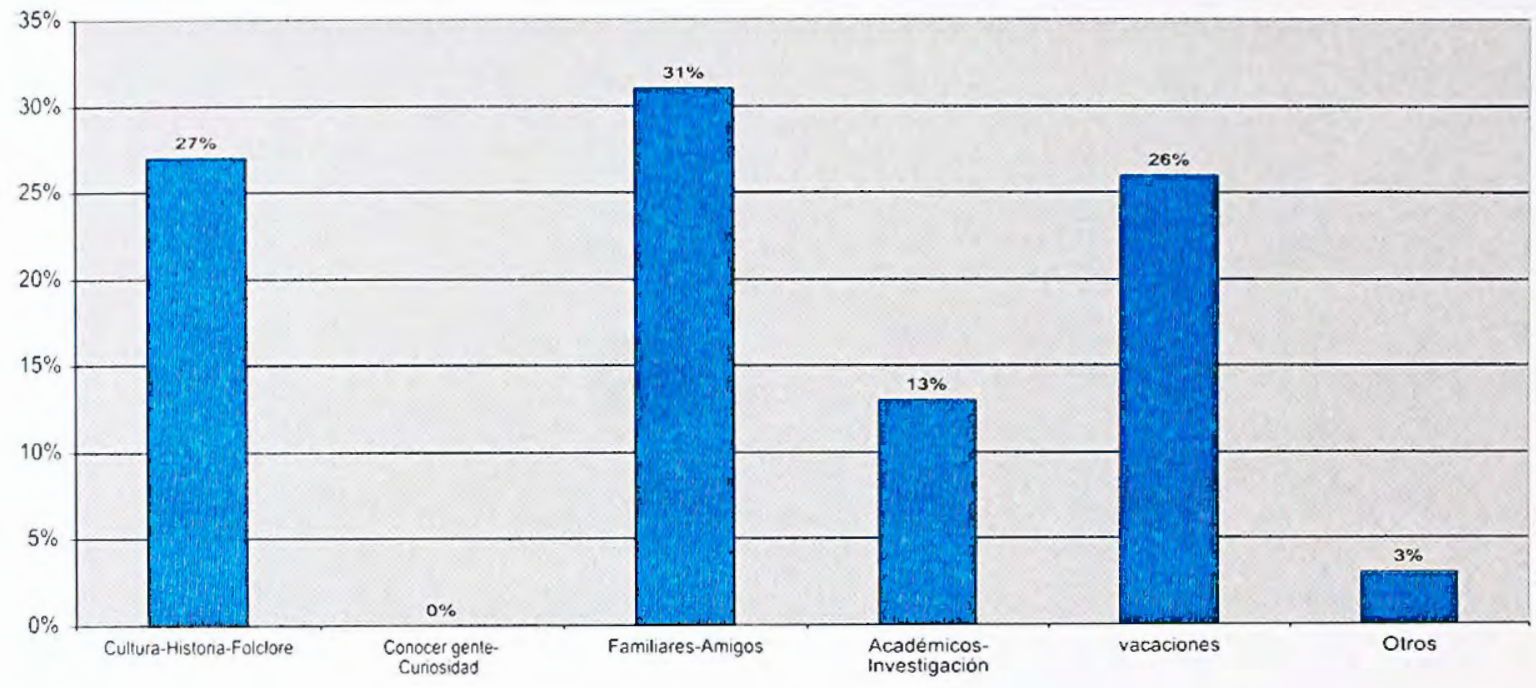

Si sumamos los dos porcentajes anteriores tenemos el $57 \%$, más de la mitad de los turistas alemanes, que encuentra cómodo un viaje por estas razones.La decisión de viaje quizás, en este caso, no obedece tanto a cuestiones financieras, como a la existencia de vinculaciones parentales en el Perú.Nos estamos refiriendo a ciudadanos alemanes procedentes de matrimonios biculturales, cuya visita al Perú, es más que un disfrute de la tranquilidad sino una rutina, parte de su vida.

Los costos económicos, aún cuando los billetes de avión son costosos, se reducen un tanto, porque la permanencia en el Perú es en casa, justamente de la familia peruana. Los viajes Ilamados " extras " realizados a otras zonas del país, son de hecho, por cuenta del visitante.

Este grupo de viajeros, por lo general, llega al Perú solo con el billete de avión Alemania-PerúAlemania, y estando en el país decide extender o no su visita a otros departamentos. La ventaja que tiene este sector de turistas es el conocimiento del castellano y de la cultura peruana, no en vano tiene un conyuge y descendencia bicultural, que le permite un desenvolvimiento bastante competente en el Perú.

La oferta cultural, la historia y la arqueología representan el $27 \%$. Sin embargo encontramos una interesante diferenciación entre el $50 \%$ de los que manifestaron la posibilidad de un eventual viaje al Perú por razones culturales y la real motivación cultural de este viaje que alcanza tan solo un poco más de la mitad. La confrontación entre la declaración eventual del entrevistado y la realidad se deja sentir una vez más. Nos aventuramos a afirmar que el concepto de turismo cultural engloba algunos mitos de significado de lo que es la cultura, como son la formación e instrucción.Estos son seleccionados en primera instancia como causa de viaje ideal a otro país, pero después se diluyen frente a la realidad. Por ejemplo, países muy claramente definidos por su atracción cultural para el turista alemán son Egipto e Italia.

La motivación de conocer gente y curiosidad por lo desconocido que en el diagrama $N^{\circ} 16$ alcanzaba 
el $28 \%$, desaparece completamente como causa de viaje de turismo. Ningún entrevistado mencionó un viaje al Perú para conocer gente.

El tiempo de permanencia en el Perú, por lo general, es de 3 a 6 semanas con el $67 \%$, periodo coincidente con las vacaciones europeas. Este es el grupo de las familias biculturales que también visitan otros lugares del Perú.

El lugar más visitado ( Ver diagrama $N^{\circ} 18$ ) es Lima con el $31 \%$. Por cuestiones logísticas es el punto de entrada al país a través del aeropuerto Jorge Chávez. El 57\% que llega al Perú por causas familiares o amicales, o bien permanece en Lima, donde tiene su centro de referencia, o al cabo de un día o dos viaja a la ciudad de su destino.

El $27 \%$, que llega por fines culturales permanece en Lima 2 o 3 días La atracción de Lima es principalmente lo colonial con las visitas a la catedral, las iglesias, y los museos. Las excursiones a los barrios antiguos de Lima (Rimac, Barranco) son otros de los atractivos turísticos de interés. Las visitas a los distritos modernos de Miraflores, y San
Isidro están totalmente garantizados, pues el alojamiento en hoteles u hostales está ubicado en dichazona.

La segunda zona de interés para ambos sectores es la ciudad del Cusco con el $22 \%$.En el primer grupo, "bicultural"cuando la visita es por primera vez, una excursión a la zona arqueológica de Machu Picchu es imprescindible. En las visitas posteriores va perdiendo motivo de interés.

El segundo grupo "fines culturales" encuentra en estas zonas un encuentro con el pasado donde respirar paz y tranquilidad. Algunos comentarios afirman lo siguiente:

"..visitar Machu Picchu es la sensación de admiración por el hombre que he podido sentir.Siento paz allí, aunque a veces hay mucha gente.."

"..no entiendo como gente como nosotros haya podido construir y transportar bloques tan gigantescos de piedra. Lo enigmático es que hasta hoy no se ha podido descubrir como lo han podido hacer. Es fantástico no?..."

\section{Diagrama $N^{\circ} 18$ Ciudades de atracción turística en el Perú}

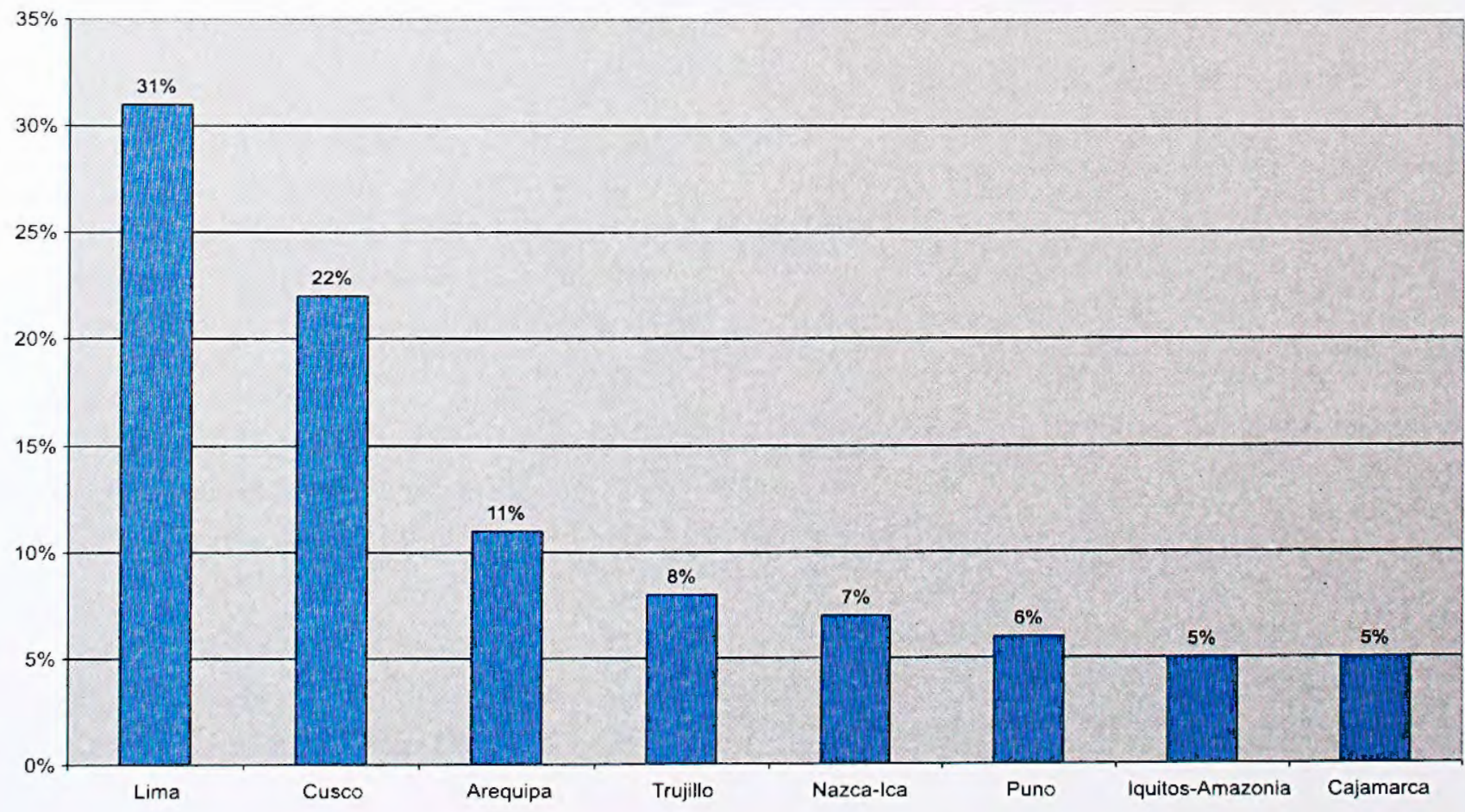


Pero el Cusco, no sólo es admirado por su riqueza arqueológica, sino también por su entorno ecológico y natural lleno de flora y fauna entrecruzado por valles y ríos que le dan una atracción especial. Son bastantes conocido especialmente por gente joven los Caminos del Inca y el valle de Pisac.

Arequipa, ocupa con el $11 \%$ el tercer lugar de interés turístico, como ciudad, aunque menos conocido por el Convento de Santa Catalina.La ciudad de trujillo con la ciudad de barro en Chan Chán con el $8 \%$ ocupa también un lugar no desestimable. Un atractivo adicional son sus playas, el sol y el buen clima.

Otras ciudades mencionadas por los turistas son Ica-Nazca con el 7\%, Puno con el 6\%, Cajamarcay la Amazonía con el 5\%, Ayacucho con el $2 \%$, y Junín con el Valle del Mantaro, entre otras.

Identificando las declaraciones, sobre las impresiones del Perú, los turistas dieron las siguientes afirmaciones:

\section{Imagen e impresiones positivas.}

Ecosistema variado con maravillosa naturaleza y altas montañas.

Iniciativa fuerza y creatividad de la población.

Solidaridad, cordialidad y simpatía de la población.

Oferta cultural: historia, arqueología y tradición.

Oferta de artículos artesanales a buenos precios.

\section{Imagen e impresiones negativas.}

Inseguridad, engaño, ladrones, criminalidad y violencia.

Transporte inseguro, impumtual, antiguo $y$ contaminado.

Poca infraestructura: edificios y hospitales.

Fuertes ruidos, caos y suciedad.

Trabajo de los niños en la calle, mendicidad y enfermedades de la piel de los mismos.
Acoso y perturbación de parte de vendedores ambulantes, mendigos y "artistas" en las vías públicas y medios de transporte.

Irrespeto para la turista alemana que viaja sola.

Excesiva burocracia para la renovación de visas y accidentes de tráfico.

\section{Información sobre el Perú.}

El $42 \%$ de los entrevistados tenía información sobre el Perú, el $50 \%$ no responde a la pregunta y el $8 \%$ dice carecer de información.

El sector que no responde a la pregunta nos está indicando dos cosas : que considera irrelevante la pregunta, o que no existe presencia del Perú para el turista alemán. Lo que si podemos afirmar es que el eventual turista alemán cuando tiene información no la descarta, sino que la analiza, cuestiona e incorpora en la agenda de posibilidades turísticas.

Es el desconocimiento o falta de información sobre el Perú lo que hace que las apreciaciones del turista alemán giren entre dos polos. Por un lado, el reconocimiento de la gente especializada e informada de la grandeza cultural y vivencial del Perú y por otro lado, la asignación de conceptos totalmente ajenos a la realidad.

El medio más utilizado para obtener información sobre el Perú ( Ver diagrama. $N^{\circ} 19$ ) , es el internet con el $31 \%$.El acceso a la informática es el medio más rápido y con más posibilidades que ofrece datos de toda clase y en todos los idiomas. La era del internet logra la conexión directa entre el consumidor final con el proveedor (un destino, un hotel o una casa rural ). Antes se pensaba que una simple web era para ganar presencia en internet, ahora "está demostrado que eso no basta, resulta cada vez más importante la asociación entre empresarios turísticos, especialmente, entre los medianos y pequeños para que sumen fuerzas en conjunto $y$ formen un gran portal sobre los nuevos destinos. 


\section{Diagrama №19 Fuentes de información sobre Perú}

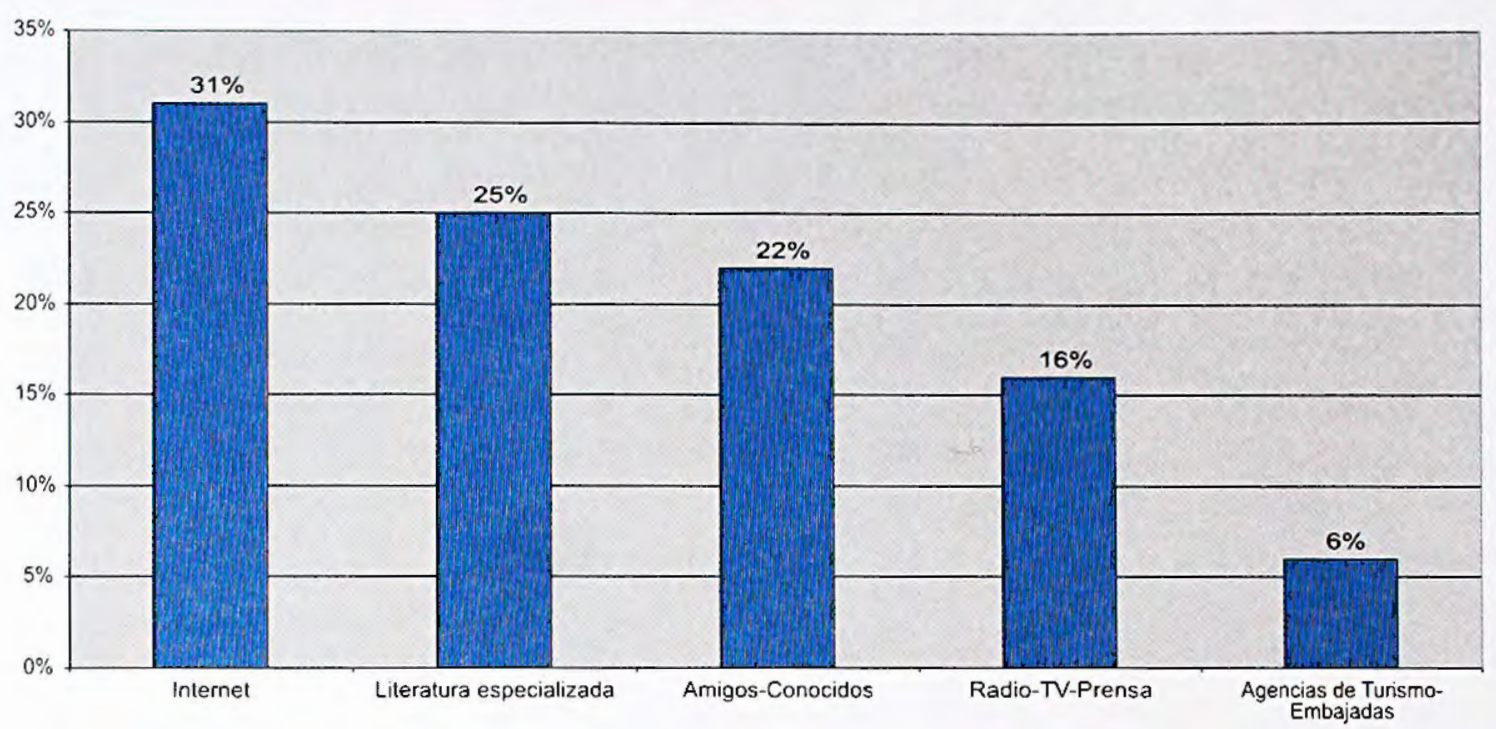

La segunda fuente de consulta es la literatura especializada con el $25 \%$. La visita a las bibliotecas - la compra de guías de turismo son necesarias antes del viaje a Latinoamerica. La información personal proveniente de amigos o conocidos que hayan estado en el Perú es el $22 \%$. Esta es también una muy buena garantía para la decisión de viaje Además la propaganda y los buenos recuerdos juegan un rol importante.

La prensa hablada y escrita representa el $16 \%$. Ambas no son, en muchos casos, las mejores embajadoras de una promoción turística. La información se presenta muchas veces bastante parcializada con la lectura de sucesos catastróficos que desvirtuan la realidad del país.

En algunos canales de televisión se ofrecen documentales sobre el Perú elaborados por empresas europeas: alemanas, francesas o inglesas. Por lo que una buena coordinación peruana-europea beneficiaría la promoción turística del Perú en el extranjero.

El 6\% correponde a la información proporcionada por las agencias de turismo, y representaciones diplomáticas en el extranjero.

\section{El Perú en relación con América Latina.}

Un conocimiento general sobre América Latina no es ajeno al turista alemán.El $40 \%$ manifestó tener información así como también haber estado en algún país de América Latina. El $60 \%$ declaró no tener ninguna referencia al respecto.

Cuando decimos conocimiento nos referimos al conjunto de datos y/o bibliografía que el turista maneja. No es un conocimiento especializado, pero si una información bastante seria y responsable sobre América Latina.

La posibilidad de visitar, por lo menos, otro país de América Latina, en un eventual viaje a Perú es del $67 \%$. Las razones son bastante claras y comprensivas: la distancia, el costo del billete de avión y la opotunidad de aprovechar las conexiones a través de los Andes en el caso de Ecuador, Bolivia y Perú; y los medios fluviales entre Uruguay y Argentina.

Los países que visitaría el turista, además de una visita al Perú, serían:Chile con el $23 \%$, Bolivia con el $18 \%$, Brasil con el $16 \%$, Argentina con el $14 \%$, Ecuador con el $6 \%$, Colombia y Venezuela con el $5 \%$, México con el $4 \%$,y demás con el $2 \%$.

La variedad de países es bastante amplia pero centrada básicamente en los andinos. Con Chile la comunicación más atractiva es cruzando Arequipa, Tacna y Arica; y con Bolivia atravesando el lago Titicaca.Los amantes de la naturaleza extienden su viaje al Brasil por la Amazonia Los que quieren 
conocer ciudades "más modernas" complementan el viaje al Perú con el circuito Brasil, Argentina y Uruguay.

\section{Conclusiones.}

El presente estudio reune los resultados cuantitativos y cualitativos de una investigación realizada en la ciudad de Berlín (Alemania), durante los meses de Octubre del 2002 a Febrero del 2003.

El universo de estudio estuvo constituído tanto por los alemanes residentes en Berlín que tenían cierta conexión con el Perú, como por aquellos que nunca habían estado en el Perú.

La técnica de investigación utilizada fue la aplicación de un cuestionario a 217 persona en centros de trabajo, universidades, academias de idiomas, bibliotecas, instituciones o asociaciones gremialistas, y al ciudadano alemán en general en los diferentes distritos de la ciudad.

Conclusiones del analisis de datos son:

\section{Perfil del eventual turista alemán.}

El $60 \%$ de los potenciales turistas son varones.

El $46 \%$ tiene entre 35 y 50 años.

El $71 \%$ son empleados o independientes.

El $47 \%$ corresponde a una población soltera.

El $42 \%$ cuenta con un ingreso anual entre 30,000 y 60,000 euros.

\section{Características del viaje de turismo.}

El $65 \%$ de los potenciales turistas alemanes tiene una habitual tendencia de viaje al extranjero.

El $44 \%$ planifica el viaje con una anticipación de uno a tres meses.

El $43 \%$ organiza el viaje por su cuenta.

Los siguientes aspectos son tomados en cuenta: al elegir un país como destino turístico:

La oferta cultural

La infraestructura turística.

La playa.

La tranquilidad.

El ecosistema.

\section{Presencia en América Latina.}

El $60 \%$ de los entrevistados visitó algún país de América Latina.
Los países más visitados fueron: Area de Centroamérica, Chile, Argentina, Uruguay, Perú, Bolivia, Ecuador, México, Brasil, Paraguay, Venezuela y Colombia.

4.El Perú "como posibilidad de destino turístico" El $42 \%$ del $63 \%$ de los que no fueron al Perú manifestó su deseo de viajar al Perú.

Los principales motivos de una posible visita al Perú serían:

La oferta cultural : historia y arqueología. La curiosidad y deseo de conocer gente. Las redes familiares y de amigos. Los académicos e investigación. Las vacaciones.

\section{El Perú como destino de visita turística.}

El $21 \%$ de los entrevistados estuvo de visita en el Perú.

Los motivos del viaje fueron:

Las redes familiares y amigos.

La oferta cultural:historia y arqueología.

Las vacaciones.

Los académicos e investigación.

El $67 \%$ de los que visitaron el Perú lo hicieron por un tiempo entre tres a seis semanas. Las ciudades de interés turístico son:

Lima
Puno
Cusco
Cajamarca
Arequipa
Iquitos
Trujillo
Valle del Mantaro
Nazca
Ica
Piura.

Las atracciones turísticas mas visitadas son:

Machu Picchu.

Lima(catedral-museos)

Chan-Chan

Paracas-Ballestas

Nazca

Amazonía

Santa Catalina.

El $42 \%$ tenía información sobre el Perú, el 50\% no responde a la pregunta y el $8 \%$ carece de información. 
El medio más utilizado para obtener información sobre el Perú es el internet,la literatura especializada, los amigos y conocidos, y la prensa hablada y escrita.

\section{El Perú en relación con América Latina}

El $67 \%$ manifestó su deseo de visitar otro país de América Latina. En un posible viaje al Perú. Los países que visitaría el turista alemán serían por orden de preferencia Chile, Bolivia, Brasil y Argentina.

El tipo de turismo a realizar en el Perú sería el histórico cultural, el ecológico, de aventura, rural y participativo.

\section{BIBLIOGRAFÍA Y FUENTES DE CONSULTA.}

ADERHOLD,Peter (2002), Entwicklung der touristischen Nachfrage vor dem Hintergrund der Terroranschläge und deren Folgen, Forschungsgemeinschaft Urlaub und Reisen e.V.F.U.R.

ANSIÒN,Juan (2000) Educar en la interculturalidad, en Pàginas $N^{\wedge} 165$, Vol XXV.

ARANTES,A,(1984): Produzendo o passado, Brasiliense, Sao Paulo.Desigualdad y diferencia,cultura y ciudadanía en tiempüos de globalización,en La dinámica globallocal.Ed.Ciccus-La Crujía, Bns. Aires.

CANCLINI GARCIA,N ( 1989): La globalización imaginada, Pidos, Buenos, Aires.

COHEN, Bruce, ( 1998): Introducción a la sociología,México, Mc Gran Hill, México.

COHEN; E ( 1972) " Toward a sociology of international tourism" Social Research, 39:164:82.

CARRERAS,C., (1996):Turismo urbano:el efecto de los megaeventos, en Turismo $y$ Geografía: reflexiones teóricas y enfoques regionales.editora Hucitee,Sao Paulo.

DUYSENS,B,(1989)"Turismo ,ocio y cultura juvenil:El caso del tuirismo de mochila en La Gomera (Canarias), Eres ( Antropología), 1 (2): 115-125.
FORSCHUNGSGEMEINSCHAFT URLAUB

UND REISEN e.V. R.A.(2004) Die 34 Reiseanalyse RA 2004., Erste Ergebnisse ITB 2004 Berlin. Kiel, Deutschand

FORSCHUNGSGEMEINSCHAFT URLAUB UND REISEN e.V. RA.(2003). Die 33 Reiseanalyse RA 2003. Erste Ergebnisse ITB 2003 Berlin. Kiel, Deutschand.

FERNÀNDEZ FUSTER, L ( 1985) Introducción a la teoría y técnica del turismo, Madrid Alianza.

GAVIRIA, Mario ( 1978): " Los procesos de decisión en la producción y consumo del espacio y tiempo turístico" en Información Comercial española 533:52-63

HONKO, Lauri,(1996):Las tradiciones en la construcción de la identidad cultural y estrategias de supervivencia étnica. Revista de Investigacion Folclóricas, $\mathrm{Vol} 11, \mathrm{~N}^{\circ} 1$.

INSULSA,José Miguel ( 2000) “Globalización América Latina y los desafios del nuevo milenio"

JAFARI, J.(1994), " La cientifización del turismo",Estudios y Perspectivas en Turismo, 3 (1) : 7-36.

JURDAO ARRONES,F.( comp) ( 1992) Los mitos del turismo, Madrid, Endymion.

LEA,J.( 1998), "Tourism and development in the Third World",Nueva York, Rourledge.

LUMBRERAS; Luis, (1999): Turismo sustentable y desarrollo local, en Turismo comunidades locales y desarrollo sustentable, DESCO,CEIDIS, Rosa Dierna,(ed).

LOHMANN,M \& DANIELSSON,J, (2003), Urlaubsmotive,,F.U.R.e.V.Kiel, Deutschland.

OLIVEN,R (1999) :Nación y modernidad.La reinvención de la tradición gaucha en el Brasil,Eudeba,Buenos Aires.

SANTANA,Agustín, (1997),Antropología y Turismo,Nuevas hordas viejas culturas., Ed.Ariel, S.A. Barcelona. 
SMITH,M (1992),"Beach resort evolution: Implications for planning" Annals of Tourism Research, 19 (2): 304-322.

TUROK, Martha, (1987): Los maestros y las culturas nacionales,SEP,México.

WEVER,Alfredo, (1935) Historia de la cultura, F:C:E. México.

WILLIAMS,R,(1980):Marxismo y Literatura, Ediciones Península, Barcelona.

YIANNAKIS,A y GIBSON, H.( 1992) "Roles tourists play" Annales of Tourism Research, 19 (2): 287-303.

\section{En Internet:}

Www.freitzeitforschung.at/Forschugsarchiv/0 2_2001/body_02_2001.html.Institut

www.fur.de.

www.wirin.de/themen/reise/artikel11.php.

www.drv.de

www.carbow-fb.de/dipl.pdf.

www.itb-berlin.de

Www.zeit.de/2004/15/Serie_Urlaub_machen

Www.tourismwatch.de/es/3esp/3esp.indigena s/content

www.naya.org/ar

www.tourismforum.scb.se

Www.revistadelsur.org.uy 